\title{
Foreign Direct Investment and Democracy: A Robust Fixed Effects Approach to a Complex Relationship
}

\author{
Rodolphe Desbordes ${ }^{\ddagger}$ Vincenzo Verardi ${ }^{\S}$
}

\begin{abstract}
We develop a new robust-to-outliers dummy estimator that we subsequently apply to investigate the impact of various democratic attributes on foreign direct investment (FDI) in recent years. We find that democracy has generally a positive impact on FDI, once outliers are controlled for, but that this relationship is very specific to each host country's characteristics.
\end{abstract}

Keywords: foreign direct investment, democracy, S-estimator, categorical variables, Stahel-Donoho estimate. JEL codes: C13, C23, F23, D70.

\footnotetext{
$\ddagger$ University of Strathclyde. Corresponding author. Address: Department of Economics, Sir William Duncan Building, University of Strathclyde, 130 Rottenrow, Glasgow G4 0GE, Scotland, United Kingdom. Telephone/Fax number: (+44) (0)141 548 3961/4445. E-mail: rodolphe.desbordes@strath.ac.uk

$\S$ : University of Namur (CRED) and University of Brussels (ECARES and i-cite). Address: Rempart de la Vierge, 8 , B-5000 Namur, Belgium. E-mail: vverardi@fundp.ac.be
} 


\section{Introduction}

The impact of democracy on foreign direct investment (FDI) in developing countries is a hotly debated issue. Jensen (2003, 2008) and Azémar and Desbordes (2009) provide an overview of the literature on FDI and democracy.

On the one hand, it has been argued that democratic forms of government attract FDI because they tend to be predictable and credible, thanks to vertical and horizontal accounting mechanisms. The combination of periodic elections and widespread diffusion of information ensures that politicians make clear their preferences, do not renege on their promises once in power, and, more broadly, do not abuse their position for private gains. Strong checks and balances increase policy stability, and ultimately the protection of property rights, because the existence of several distinct veto players hinders any changes in the status quo. When policy changes do occur, institutionalised channels of influence/lobbying can allow foreign investors to mitigate any adverse effects. Consolidated democracies also guarantee orderly and non-violent changes of government within the current institutional framework.

On the other hand, the virtues of democracy can easily be seen as disadvantages to countries wanting to attract multinational enterprises (MNEs). Politicians' desire to win the elections may lead them to promise and adopt popular but economically harmful policies. Political turnover creates uncertainty about the persistence of policies, whereas an increase in the number of veto players has the potential to result in long-term reform sclerosis. Foreign firms may suffer from a political liability of foreignness and be discriminated against relative to their better politically-connected domestic competitors. Finally, a related but more sinister view is that freedom of expression and open media can prevent foreign firms from colluding with officials in order to obtain generous entry deals or to decrease market competition. Hence, FDI may be attracted by autocracies.

This ambiguous theoretical impact of democracy on FDI is mirrored in the empirical literature. As described in Table 1, studies find positive (Harms and Ursprung, 2002; Jensen, 2003; Busse, 2004; Azémar and Desbordes, 2009), negative (Li and Resnick, 2003), or insignificant (Blanton and Blanton, 2007; Büthe and Milner, 2008; Choi and Samy, 2008) impacts, depending on the econometric model, the proxy for democracy, and the sample used.

The presence of outliers, i.e. observations which are substantially different from the bulk of the data, has sometimes been blamed for this variety of findings. Some researchers have attempted to deal with these atypical observations (Jakobsen and De Soysa, 2006; Choi, 2009; Li, 2009). How- 


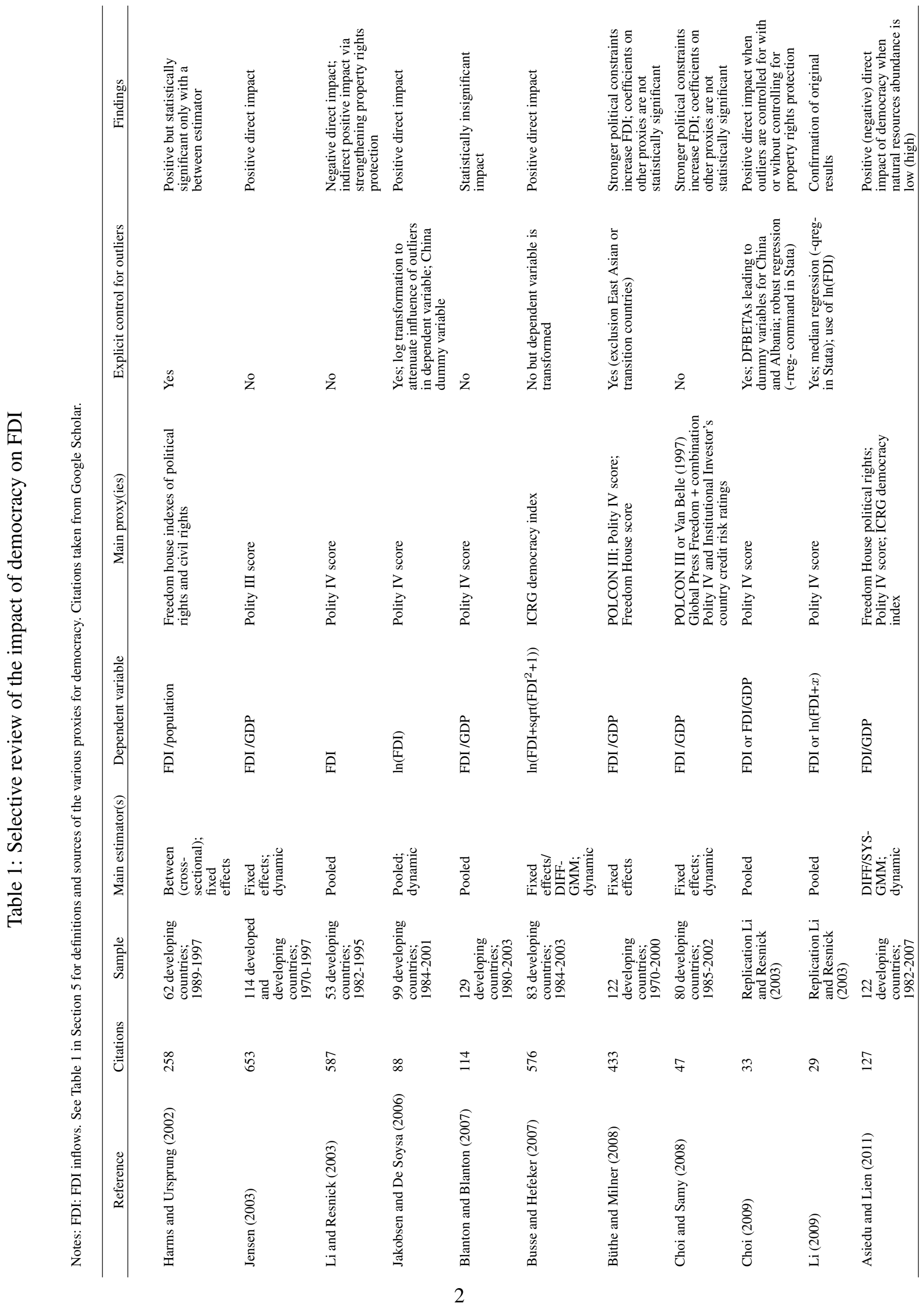


ever, it is unlikely that they have solved this issue in a satisfactory manner. Popular robust estimators (e.g. median regression estimator or M-estimator) are sensitive to outliers present in the values of explanatory variables and outlier diagnostics (e.g. the Cook Distance) frequently fail to detect atypical observations as they fundamentally rely on the extremely non-robust-to-outliers least-squares estimator (Verardi and Croux, 2009). Problems of inadequate econometric identification and treatment of outliers thus remain pervasive in the FDI literature.

A related issue is the increasing use of the fixed effects estimator in order to control for unobserved time-invariant unit-specific effects which may be correlated with the explanatory variables. While this estimator may reduce any omitted variable bias, it does not protect against outlier contamination. An aggravating problem is that the most resistant robust regression methods are ill-designed to analyse econometric models which include a large number of dummies. While some robust panel data estimators have been proposed, they appear not to be consistent when the number of time periods is small, and cannot deal with dummies not related to the within transformation (Aquaro and Pavel, 2010).

In this paper, we revisit the link between FDI and democracy in developing countries, during the 1998-2006 period. We pay particular attention to the multi-faceted nature of democracy, the influence of outliers, and the heterogeneous relationship that may exist between these two variables. We use a variety of measures to explore how each particular dimension of democracy can influence FDI. We develop a new robust dummy estimator, which allows us to control for outliers in a fixed effects panel data model. Finally, we investigate whether the impact of democracy on FDI depends on natural resources, income inequality, and their interaction. Our results show that democracy has generally a positive impact on FDI, once outliers are controlled for, but that this relationship is very specific to each host country's characteristics.

The rest of the paper proceeds as follows. Section 2 introduces our new robust dummy estimator and explains its advantages over existing robust regression methods. Section 3 provides Monte-Carlo simulations highlighting the good performance of our estimator. Section 4 replicates a key study on FDI and democracy in order to highlight that the correct treatment of outliers is a key issue. Section 5 describe the data used in our original empirical analysis and motivate our econometric approach. Section 6 presents and interprets our empirical results. Section 7 concludes. 


\section{The robust dummy estimator}

The objective of linear regression analysis is to examine how a dependent variable is linearly related to a set of explanatory variables. Technically speaking, it consists in estimating the vector $\theta$ of unknown parameters in:

$$
y=X \theta+\varepsilon
$$

where $y$ is the dependent variable and $X$ is the $(n \times p)$ matrix of regressors. Matrix $X=\left(X_{1}, X_{2}\right)$ is composed of two blocks: $X_{1}$ that is the $\left(n \times p_{1}\right)$ matrix of dummy variables and $X_{2}$ that is the $\left(n \times p_{2}\right)$ matrix of the continuous variables $\left(p=p_{1}+p_{2}\right)$.

On the basis of the estimated parameters $\hat{\theta}$, it is possible to predict the dependent variable $\hat{y}$ and to fit the residual $r_{i}=y_{i}-\hat{y}_{i}$. Although $\theta$ can be estimated in several ways, the underlying idea is always to try to get as close as possible to the true model by minimising an aggregate measure of dispersion of the residuals. In the case of the well-known ordinary least squares (LS) estimator, the measure of spread used is the variance. The vector of parameters estimated by LS is therefore:

$$
\hat{\theta}^{L S}=\arg \min _{\theta} \sum_{i=1}^{n} r_{i}^{2}(\theta)
$$

A well-known feature of the variance (and consequently of LS) is that it is extremely sensitive to the presence of outliers. To take this into account, Rousseuw and Yohai (1984) propose another estimator, a S-estimator, that is based on the minimisation of another measure of dispersion $s$ of the residuals, an M-estimator of scale.

An M-estimator of scale is a very general class of estimators of dispersion that do include the variance. Indeed, the M-estimator of scale is defined as a value of $s$ satisfying equality

$$
\frac{1}{n} \sum_{i=1}^{n} \rho\left(\frac{r_{i}(\theta)}{s}\right)=\delta
$$

where $\delta=E[\rho(Z)]$ with $Z \sim N(0,1)$. If we choose as $\rho$ function the square function, $\delta=1$ and this equality becomes $\frac{1}{n} \sum_{i=1}^{n}\left(\frac{r_{i}(\theta)}{s}\right)^{2}=1$ which can be re-written as $\frac{1}{n} \sum_{i=1}^{n} r_{i}(\theta)^{2}=s^{2}$ which is the definition of the variance ( $\operatorname{since} \bar{r}(\theta)=0$ ).

As previously stated, an S-estimator of regression minimises an M-estimator of scale of the residuals. Since LS minimises the variance of the residuals, the LS estimator is a special type of S-estimator. 
A common choice for the $\rho$ function in (3) is the Tukey's biweight function as defined in (4):

$$
\rho(u)=\left\{\begin{array}{c}
\frac{k^{2}}{6}\left(1-\left[1-\left(\frac{u}{k}\right)^{2}\right]^{3}\right) \text { if }|u| \leq k \\
\frac{k^{2}}{6} \text { if }|u|>k
\end{array} .\right.
$$

where $u$ corresponds to standardised residuals. The loss function of LS can still be obtained by considering a tuning parameter $k$ going to infinity, as $\lim _{k \rightarrow \infty} \frac{k^{2}}{6}\left(1-\left[1-\left(\frac{u}{k}\right)^{2}\right]^{3}\right)=\frac{1}{2} u^{2}$.

To increase robustness, the loss function should award less importance to atypical observations, i.e. observations associated with very large residuals. This is obtained by reducing the value of tuning parameter $k$. Figure 1 shows Tukey's biweights function for different values of the tuning constant. In the LS case $(k=\infty)$, the importance of the standardised residuals $u$ increases with $u$. In the other cases, the importance awarded to residuals is bounded. If one sets the tuning parameter very low, the resistance to outliers is very high but this will come at a cost since the gaussian efficiency of the estimator will be low. There is therefore a trade-off between robustness and efficiency. A common value for the tuning constant $k$ is 1.546 , which results in an estimator which has a breakdown point of $50 \%$ (i.e. an estimator that withstands a contamination of up to $50 \%$ of outliers before producing an arbitrary result).

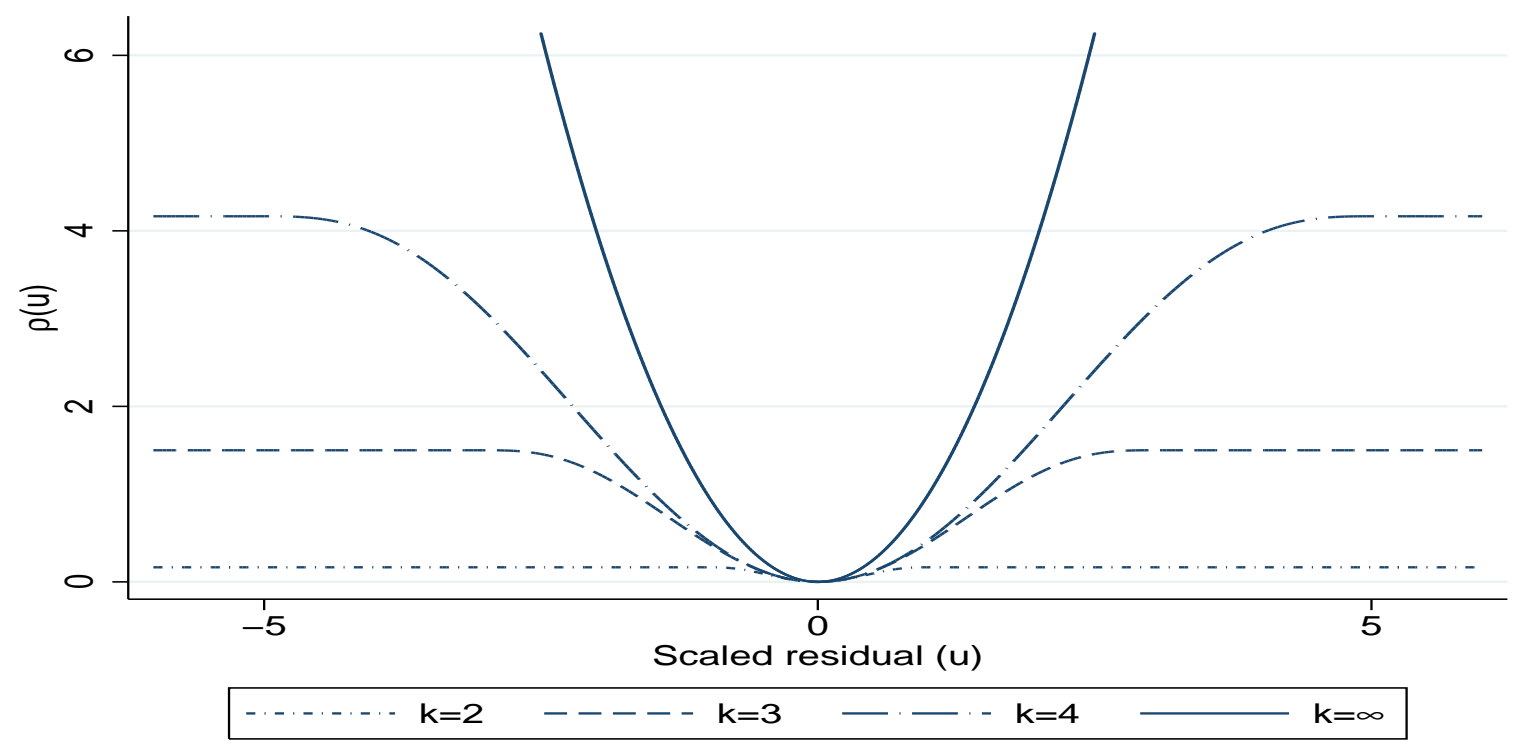

Figure 1: Tukey's biweights function for different values of the tuning constant $(k)$

Explicit formulas for $\hat{\theta}$ are generally not available and it is necessary to call on numerical optimisation based on subsampling and iteratively reweighted algorithms to find a solution to (3). Un- 
fortunately, it can be shown that these algorithms turn out to be inapplicable when several dummy variables are present, as can be the case in a fixed effects panel data setting. Indeed, as emphasised by Maronna and Yohai (2000), sub-sampling algorithms can easily lead to collinearity within subsamples if various dummies are among the regressors.

To cope with this issue, several procedures have been proposed. Rousseeuw and Wagner (1994) propose a procedure that guarantees that individuals in all the categories identified by the dummies are present in the subsets, circumventing thus the issue of perfect multicollinearity. This algorithm however leads to a great number of replications and therefore becomes excessively slow (and unapplicable) when datasets are large. Hubert and Rousseeuw (1997) suggest using a multivariate outlier detection tool to identify leverage points (i.e. outliers in the $x$-dimension) which they then apply a weight zero to, and subsequently, to use an estimator that withstands contamination on the vertical dimension (such as median regression) but that does not need to be robust against leverage points (since these have already been removed). However they focus exclusively on continuous right hand side variables.

Finally, Maronna and Yohai (2000) propose two estimators. First, The M-GM estimator, which is similar to that of Hubert and Rousseeuw (1997), but where the influence of dummies in the multivariate setup is tackled by partialling them out. This estimator has a low breakdown point. Second, the M-S estimator, which alternates two estimators: an M-estimator and an S-estimator. Regression monotonic M-estimators are easy to compute and minimise the sum of a a less rapidly increasing function of the residuals than the quadratic loss function. The drawback of these estimators is that they can only be used when outliers belong to the dependent variable and there is no outlyingness in the space of the explanatory variables (i.e. when no leverage points are present). This is the case when a continuous variable is regressed on a set of dummy variables. On the other hand, S-estimators cope well with leverage points but their practical implementation is often unfeasible when several dummies are present due to the existence of collinear sub-samples. The MS algorithm alternates therefore between an M-estimator after partialling-out continuous variables and an S-estimator after partialling-out dummy explanatory variables. The partialling-out is done using the estimated parameters obtained in the previous $\mathrm{M}$ or $\mathrm{S}$ step. A disadvantage of this method is that the algorithm has to be stopped after a set number of iterations, even though there is no guarantee that no better solution would have appeared in further replications. Indeed, as stated by Maronna and Yohai (2000), the scale (the measure of dispersion of the residuals) does not necessarily decrease after each iteration. 
To avoid these drawbacks, we advocate working with an S-estimator that has good properties and that can theoretically handle dummies. However, we propose to modify the optimisation code in a manner that avoids perfectly collinear sub-samples. The algorithm is described in details in the Appendix. Once the parameters are estimated, it is straightforward to identify outliers. This is done by calculating standardised residuals (i.e. robust residuals divided by their dispersion) and identifying those larger than a given cut-off point. The cut-off point that we use is $2.25{ }^{1}$ Having identified the outliers, we can award them a weight zero and run a standard LS regression.

In the next section, we present some Monte-Carlo simulations to show the good behaviour of the S-estimator programmed in this way.

\section{Monte-Carlo simulations}

We run three different simulations:

a. For a first set of simulations, three design variables, $X_{1}, X_{2}, X_{3}$ and an error term $u$ are generated from four $N(0,1)$ series. The dependent variable $y$ is generated according to the data Generating Process (DGP): $y_{i t}=X_{1 i t}+X_{2 i t}+X_{3 i t}+u_{i t}$.

b. For a second set of simulations, 20 dummy variables, generated from independent Bernouilli distributions $(p=0.5)$, are added to the design space. The DGP becomes $y_{i t}=X_{1 i t}+X_{2 i t}+$ $X_{3 i t}+\sum_{j=1}^{20} d_{j}+u_{i t}$

c. For a final set of simulations, a Panel Fixed Effects (FE) setup is created. Variables $X_{2}, X_{3}$ and the error term $u$ are generated from three independent $N(0,1)$ series. Variable $X_{1}$ and the individual constants are not independent and are generated in the following way:

(i) variables $X_{1}$ and $d$ come from a bivariate normal distribution $N(\mu, \Sigma)$ where $\mu=(0,0)$ and $\Sigma=\left[\begin{array}{cc}1 & 0.8 \\ 0.8 & 1\end{array}\right]$.

(ii) the $d$ variable is modified according to transformation $d=\operatorname{round}(d * 5)$ and the DGP becomes $y_{i t}=X_{1 i t}+X_{2 i t}+X_{3 i t}+d_{i}+u_{i t}$, with $\operatorname{Corr}\left(X_{1 i t}, d_{i}\right) \neq 0$. The unit-specific effects will be estimated using dummy variables.

\footnotetext{
${ }^{1}$ If the residuals were normally distributed, values above or below these cut-off points would be strongly atypical since they would be 2.25 standard deviations away from the mean (which is zero by construction), with a probability of occurrence of 0.025 .
} 
To create outliers, 10 observations for the $X_{1}$ variable are modified and randomly picked from a $N(0,10)$ series. For all simulations the sample size is 200 and the number of simulations is 1000 . In all simulations, $y$ is regressed on the $X \mathrm{~s}$ and the dummies using respectively a robust dummy estimator (the S-estimator programmed using the code we propose) and a classical LS estimator. We report

- in Figure 2, the histogram of the coefficients associated to variables $X_{1}, X_{2}$ and $X_{3}$, in all three scenarios. We call the estimated coefficients $B_{1}, B_{2}$ and $B_{3}$.

- in Tables 2 and 3, the bias and the mean squared error (MSE) of the parameters estimated using the robust dummy estimator and the classical LS estimator.

As can be seen from the simulations, the robust dummy estimator behaves well when dummies are present. All estimated coefficients are normally distributed (Figure 2) and the bias and MSE are minimal (Tables 2 and 3). On the other hand, and as expected, the least squares estimator behaves poorly in every scenario.

Table 2: Bias and MSE of the robust dummy estimator

Note: MSE: Mean Squared Error. Values for parameters B1, B2, B3: 1, 1, 1 .

\begin{tabular}{ccccccc}
\hline & \multicolumn{2}{c}{ Setup1 } & \multicolumn{2}{c}{ Setup 2 } & \multicolumn{2}{c}{ Setup 3 } \\
\hline & Bias & MSE & Bias & MSE & Bias & MSE \\
\hline B1 & -0.004 & 0.007 & -0.007 & 0.016 & -0.004 & 0.044 \\
B2 & -0.003 & 0.006 & -0.01 & 0.015 & -0.004 & 0.016 \\
B3 & -0.003 & 0.007 & -0.005 & 0.0131 & -0.015 & 0.014 \\
\hline
\end{tabular}

Table 3: Bias and MSE of the LS estimator

Note: MSE: Mean Squared Error. Values for parameters B1, B2, B3: 1, 1, 1.

\begin{tabular}{lllllll}
\hline & \multicolumn{2}{c}{ Setup1 } & \multicolumn{2}{c}{ Setup 2 } & \multicolumn{2}{c}{ Setup 3 } \\
\hline B1 & -0.829 & 0.688 & -0.806 & 0.651 & -1.001 & 1.003 \\
B2 & -0.013 & 0.006 & -0.042 & 0.007 & 0.003 & 0.008 \\
B3 & -0.119 & 0.020 & 0.091 & 0.014 & 0.008 & 0.010 \\
\hline
\end{tabular}

Having shown the good behaviour of our robust-to-outliers dummy estimator, we now investigate the robustness of the findings of a key study on the relationship between FDI and democracy. 
Figure 2: Behaviour of the robust dummy estimator
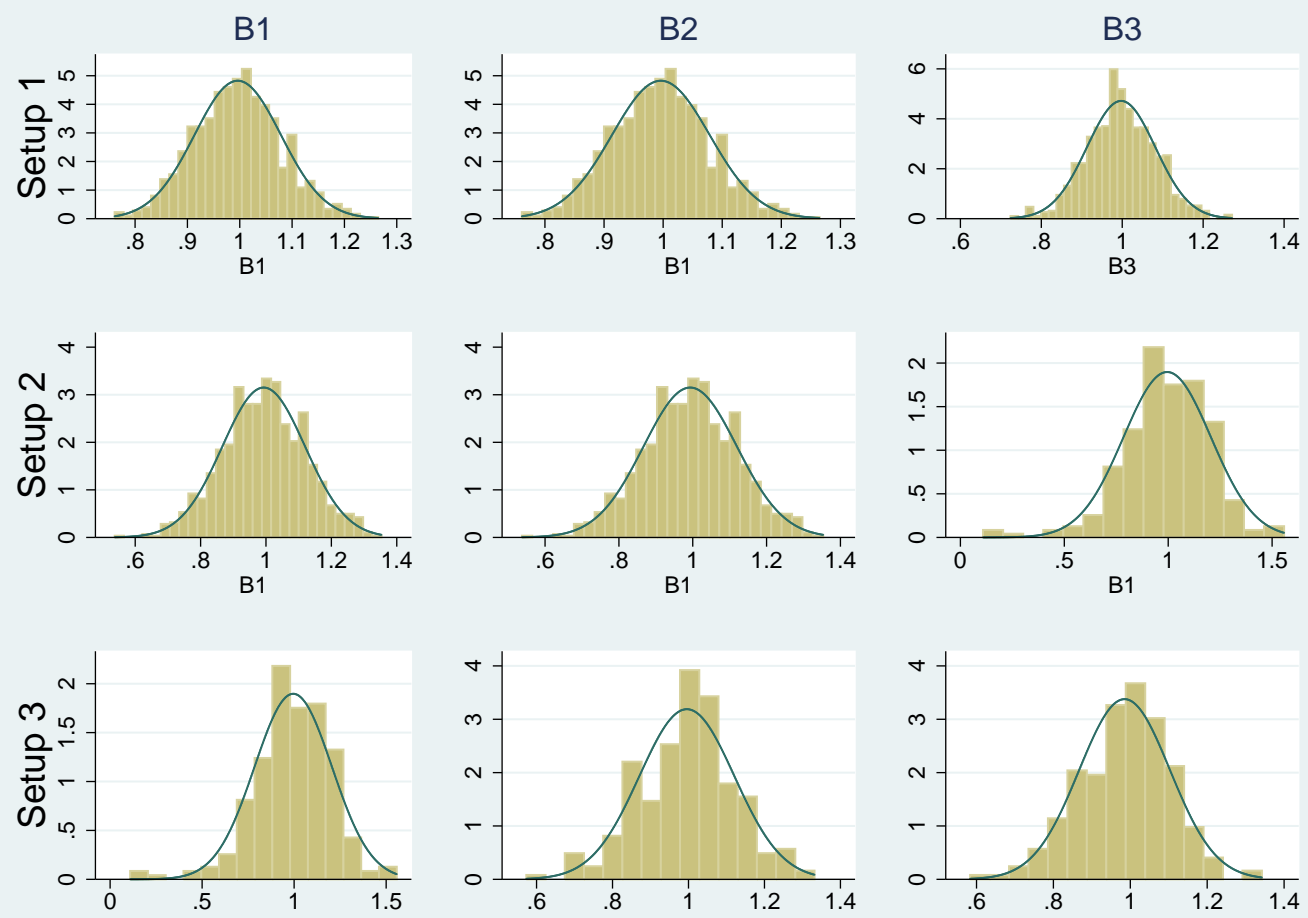

\section{Replication}

According to Google Scholar, Jensen (2003) is the most cited empirical study on the relationship between FDI and democracy. It has been cited 650 times, and, as shown in Figure 3, it remains a key reference nowadays. In this section, we investigate the robustness of this study's findings to outliers. ${ }^{2}$ The sample covers 112 countries over the period 1970-1997, the dependent variable is FDI inflows as a share of GDP, and the proxy for democracy is Polity IV score (see Table 5 for a description). We focus on the key regression of the paper: model 10 in Table 4. The estimates suggest that a fully autocratic government (score of 0 ) becoming fully democratic (score of 20) can be expected to attract $0.4 \%$ more FDI flows as a percentage of GDP. Given that the average level of FDI flows in the sample is $1.3 \%$ of GDP, this is a sizeable amount.

Table 4 presents our results. Column (1) replicates perfectly the estimates found in Jensen (2003). In column (2), we remove the observations identified as outliers by the Cook distance, which is a scaled measure of the distance between the coefficient vectors when a given observation is omitted.

\footnotetext{
${ }^{2}$ Data are downloaded from Nathan Jensen's website (http://www.natemjensen.com/ replication-data/).
} 


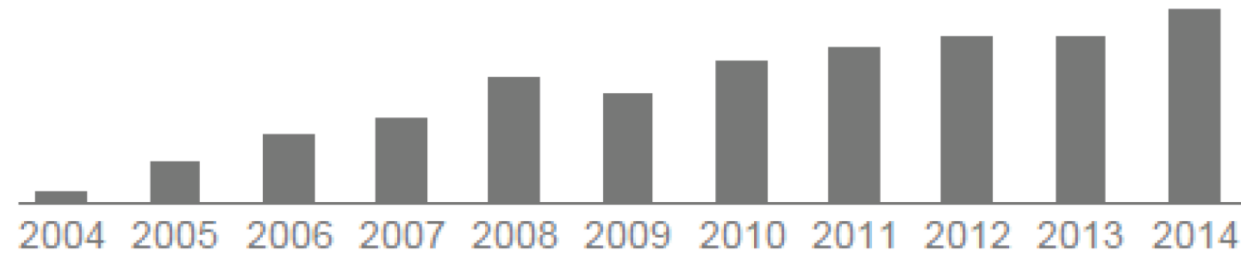

Figure 3: Citations of Jensen (2003)

Source: Google Scholar.

Five percent of the observations are deemed to be outliers. Their omission has no qualitative impact on the results. In column (3) we use an M-estimator, which gives a lower weight to observations with large standardised residuals but is no robust to leverage points. The estimated impact of democracy falls by half. In column (4), the M-estimator is used again, but the sample now only includes observations which have not been identified as outliers, and therefore potential leverage points, in column (2). This is essentially what the Stata command -rreg- is doing. Results are similar to those in column (4).

In column (5), we now use our robust-to-outliers dummy estimator. The coefficient on democracy remains positive and statistically significant. However, the estimated effect of democracy on FDI is only $25 \%$ the magnitude of the initial estimate. A fully autocratic government becoming fully democratic can now be expected to attract only $0.1 \%$ more FDI flows as a percentage of GDP. It is worth noting than the fit of this regression is much better than that of column (1): the R-squared increases from 0.613 to 0.945 . This reflects the fact that a sizeable number of observations $(25 \%)$ are not well explained by the empirical model. In column (6), the model is estimated using the outlying observations. It can be seen that the vast majority of countries had experienced atypical FDI flows. These episodes are not well predicted by past FDI flows and tend to coincide with changes in economic growth and fiscal stance. In column (7), we use the MS estimator. Results are very close to those in column $(5) .^{3}$

Figure 4 provides a way of assessing the most outlying countries. Countries are classified as outliers when the value of the mean of the residuals standardised by a robust estimate of their standard deviation is greater than 2.25 (dashed lines). The most outlying countries tend to be small countries, located in Eastern Europe, Latin America, or Sub-Saharan Africa. It is often not straightforward to

\footnotetext{
${ }^{3}$ In the final estimation stage, the M-S estimator uses all (weighted) observations whereas our robust dummy estimator omits identified outliers. This explains why the reported number of observations is different in column (5) and (7).
} 


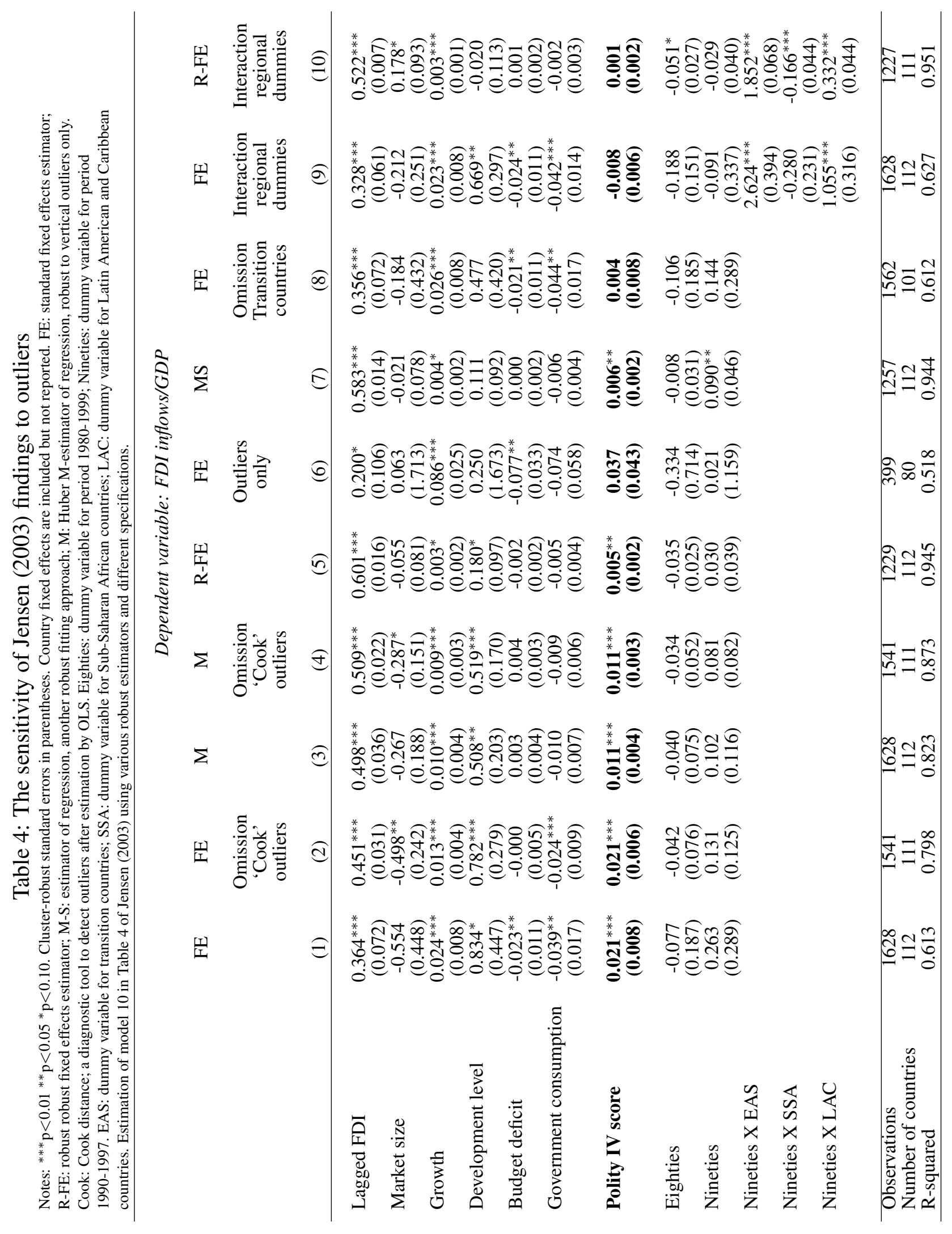


explain why some observations are outliers. However, in the case of Eastern Europe countries, it is easy to interpret their atypical behaviour as the consequence of the fall of the Berlin Wall, and their subsequent adoption of market-based economic systems with mixed results. Figure 5 shows that the Eastern Europe countries in the sample experienced a boom in FDI and rapid democratisation after the year 1989, despite deteriorating macroeconomic conditions. These two concomitant trends may explain the positive relationship between FDI and democracy identified in column (1).

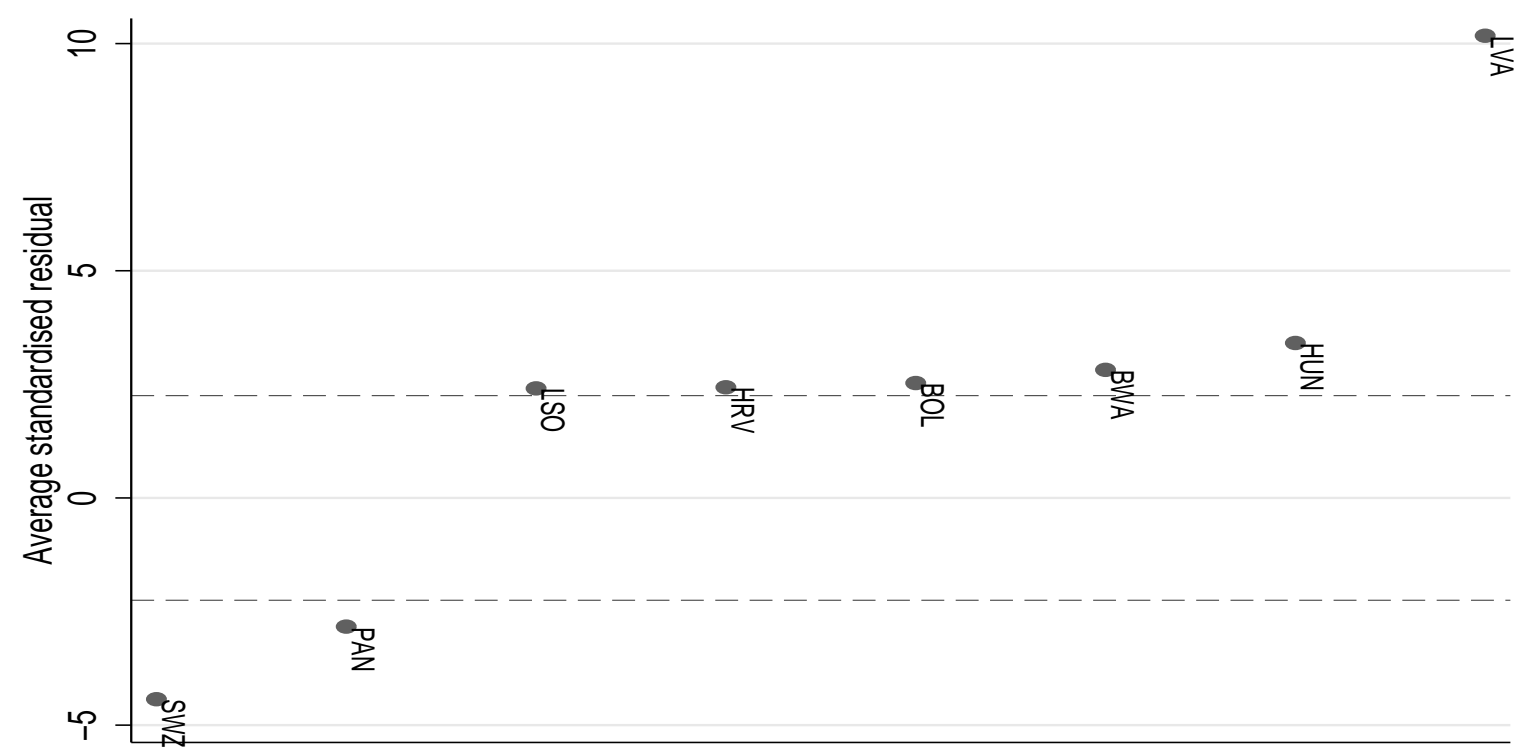

Figure 4: Large outliers

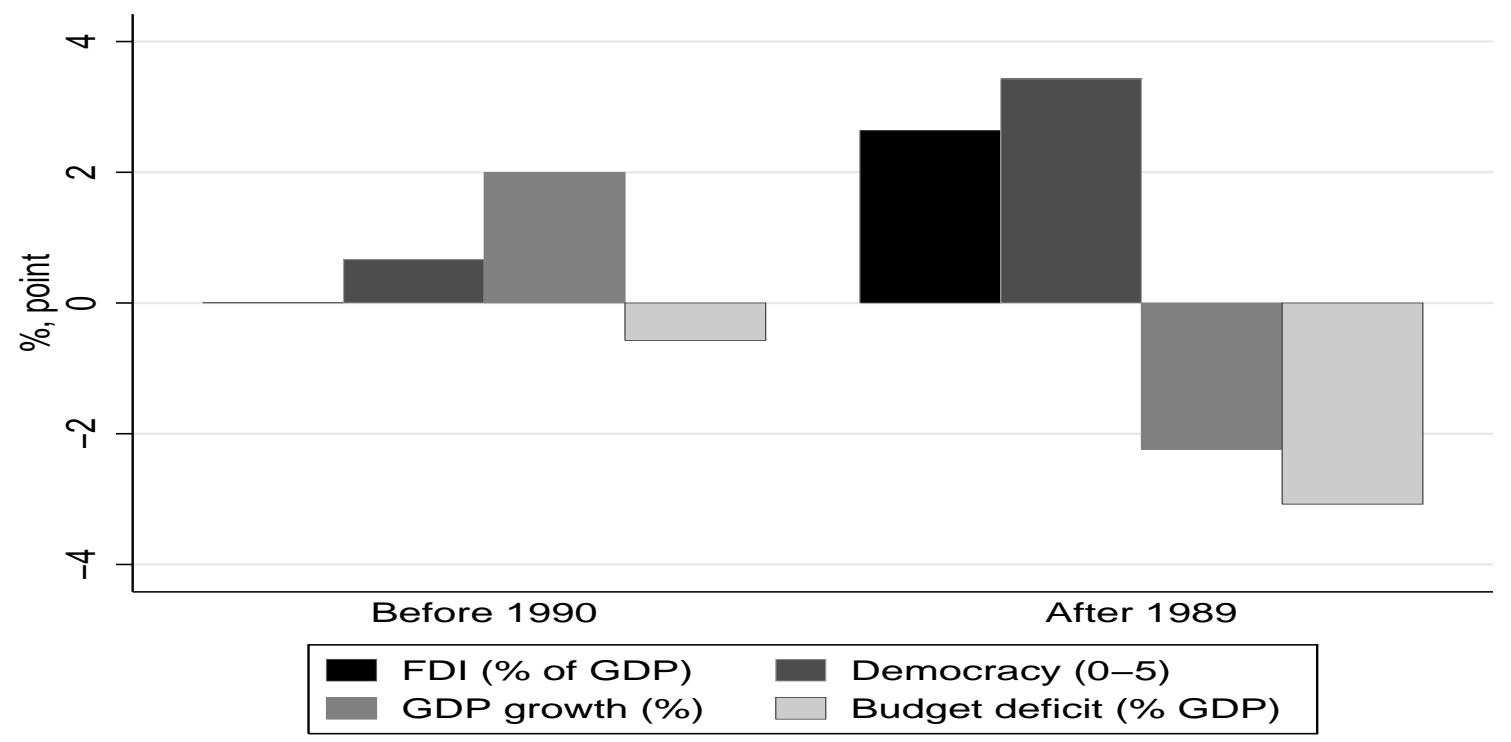

Figure 5: Key indicators for Transition countries 
We investigate this possibility in column (8) where we remove Eastern European countries from the sample (4\% of the observations). We now fail to find a statistically significant impact of democracy on FDI. It could be argued that these observations provide valuable information since they could be interpreted as encompassing a 'natural experiment' on the effects of democracy on FDI. Hence, in column (9), we use the full sample but we include interaction terms between the nineties dummy variable and three regional dummy variables (EAS: Eastern Europe; SSA: Sub-Saharan Africa; LAC: Latin America and the Carribean). In that way, we control for common effects in each region which may influence FDI and may also be correlated with democracy. The coefficients on the interaction terms indicate that the EAS and LAC regions have indeed attracted, holding other factors constant, much more FDI than other regions in the nineties. Once we control for these regional effects, the coefficient on democracy becomes negative and statistically insignificant, suggesting that democratisation occurred at the same time as the improvement of the business environment for foreign investors, but had not a direct effect on a country's attractiveness. Finally, in column (10), we estimate the model of column (9) using our robust-to-outliers dummy estimator. Relative to column (5), the number of outliers identified is roughly the same but we now fail to find a statistically significant impact of democracy on FDI.

To sum up, we initially found that the estimated impact of democracy on FDI put forward by Jensen (2003) is reduced by three-quarters when we control for outliers. The outlying observations were not identified by common robust methods and diagnostic tools. Analysis of the outliers suggested the adoption of a more flexible model, which took into account that some regions have experienced dramatic changes in their political and economic conditions. When we did so, controlling for outliers or not, we failed to find a statistically significant positive impact of democracy on FDI. Hence, the findings of Jensen (2003) seems to stem from model misspecification (a restrictive empirical model) that we were able to identify and mitigate thanks to our robust-to-outliers dummy estimator.

We now turn to our contribution to the empirical literature.

\section{The effects of democracy on FDI: empirical model and data}

Democracy is an elusive concept. Schumpeter (1942) adopted a minimalist perspective by defining it as "the institutional arrangement for arriving at political decisions in which individuals acquire the 
power to decide by means of a competitive struggle for the people's vote" (p.250). His vision revolves around the existence of contested elections, which can be interpreted as a disciplining device, but does not involve any reference to the institutional arrangements constraining the abuse of political powers between elections. These constitutional checks and balances are nevertheless often judged to be a vital democratic attribute (Munck and Verkuilen, 2002). Media freedom is also perceived as a crucial component of a well-functioning democracy as it guarantees that formal and real accountability overlap. The various proxies that we use in this paper cover these various aspects of democracy. Table 5 provides detailed information on each measure. To facilitate comparison of estimates, we normalise all variables: each proxy of democracy is rescaled to have a mean of zero and a standard deviation of one.

We will test each of these democracies proxies, using the following fixed effects dynamic panel data model:

$$
\begin{aligned}
\ln (\mathrm{FDI})_{i t}= & \gamma_{1} \ln (\mathrm{FDI})_{i t-1}+\beta_{1} \text { Democracy }_{i t}+\beta_{2} \text { Regulatory Quality }_{i t}+ \\
& \beta_{3} \ln (\mathrm{GDP})_{i t}+\beta_{4} \ln (\mathrm{POP})_{i t}+C_{i}+T_{t}+\epsilon_{i t}
\end{aligned}
$$

where $C_{i}$ are time-invariant country-specific effects, $T_{t}$ are country-invariant time effects and $\epsilon_{i t}$ is the error term. Our measure of FDI is the log of financial FDI stock (liabilities), which have been carefully compiled for a large sample of countries over the period 1970-2006 by Lane and MilesiFerretti (2007). Note that unlike the studies reported in Table 1, we use FDI stocks instead of FDI flows. As explained by Egger and Merlo (2007), theoretical models of FDI suggest that this is the appropriate dependent variable; change in the value of a given determinant leads to FDI flows until a new steady-state FDI stock is reached.

We wish to keep the sample constant across all regressors. Data for the WGI Voice and Accountability indicator start in 1996, and are only available in even years from 1998 to 2002 . We decided therefore to work with the same two-year interval dataset, whichever the measure of democracy tested. Overall, our sample covers 111 developing countries and five years: 1998, 2000, 2002, 2004, and 2006. For each country, we have therefore a maximum of five observations.

This short time dimension of our panel, the presence of a lagged dependent variable, and the inclusion of fixed effects, motivate us to keep our empirical model parsimonious. In addition to democracy, we control for four other variables. The lagged dependent variable captures the sluggish 


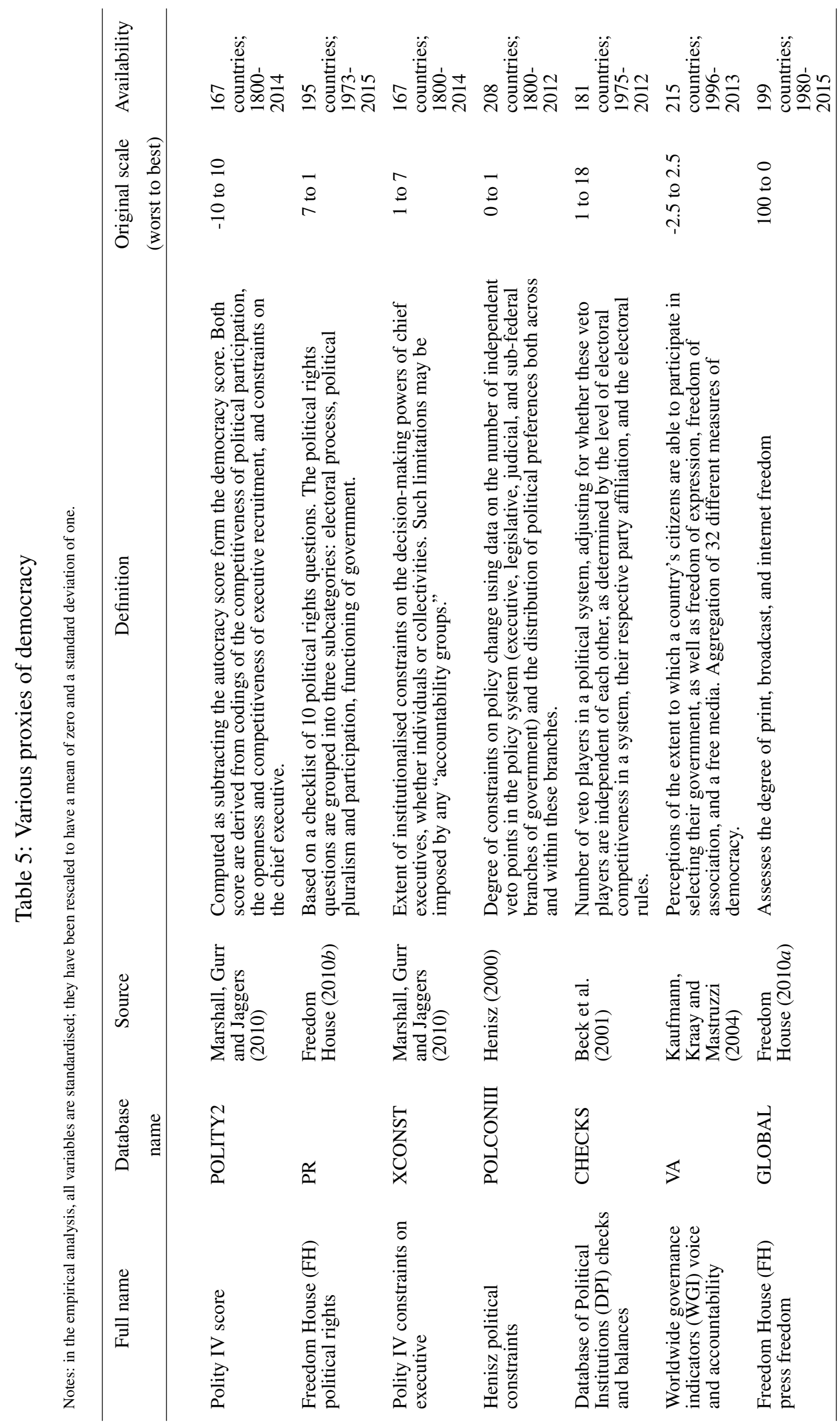


adjustment of FDI stocks towards their long-run levels over time (Kinoshita and Mody, 2001). Market size (GDP) is the most accepted determinant of FDI (Chakrabarti, 2001). The combination of GDP and population size allows to control for the level of development, which can be seen as a catchall proxy for various factors attracting or deterring FDI, e.g. consumers' purchasing power or labour costs (Benassy-Quere, Coupet and Mayer, 2007; Cheung and Qian, 2009; Lane, 2015). Finally, we include the World Bank governance measure of regulatory quality. This governance dimension has frequently been found to be one of the most statistically significant institutional determinant of FDI (Globerman and Shapiro, 2003; Daude and Stein, 2007) and is well-correlated with the different measures of democracy ( $\bar{r} \simeq 0.60$ ). We do not include other governance variables because we do not want to eliminate the channels of influence through which democratic changes can influence FDI, e.g. a strengthening of property rights protection. Lastly, we assume that other FDI determinants are captured adequately by the fixed effects, including time-invariant country characteristics which may be correlated with democracy.

It could be argued that the time series dimension of our panel is too short to identify the impact of democracy on FDI through the investigation of how changes in FDI are related to changes in democracy. However Table 6 shows that the within variation of the measures of democracy is relatively high, with values ranging between one-third and one-half of the between variation. This relatively high time-series variation indicates that many countries have experienced changes in their political regimes over the period 1998-2006. In more econometric terms, although we do not exploit the between variation of the data, the within variation of the data is high enough to allow the relatively precise identification of the parameters of our empirical model.

Table 6: Between and within components of the standard deviations of democratic proxies

\begin{tabular}{lccc}
$\begin{array}{l}\text { Notes: FH: Freedom House; DPI: Database of Political Institutions; WGI: Worldwide Governance Indica- } \\
\text { tor. Between variation: standard deviation of } \overline{x_{i}} \text {. Within variation: standard deviation of }\left(x_{i t}-\overline{x_{i}}\right) \text {.) }\end{array}$ \\
\hline \multicolumn{1}{c}{ Measure } & Between & Within & Ratio B/W \\
\hline & & & \\
Polity IV score & 0.95 & 0.26 & 0.27 \\
FH political rights & 0.95 & 0.29 & 0.31 \\
Polity IV constraints on executive & 0.95 & 0.30 & 0.32 \\
Henisz strength of veto players & 0.90 & 0.43 & 0.48 \\
DPI strength of veto players & 0.92 & 0.40 & 0.43 \\
FH press freedom & 0.93 & 0.33 & 0.35 \\
WGI voice and accountability & 0.96 & 0.24 & 0.25 \\
\hline
\end{tabular}


It is well known that the fixed effects estimator for dynamic panel models is biased and inconsistent for fixed $T$ time periods, due to the correlation of the within transformed lagged dependent variable with the within transformed error term (Nickell, 1981). Using instrumental variables methods to obtain consistent estimates would singularly complicate the implementation of our robust-to-outliers dummy estimator and distract us from our main focus. We circumvent this issue by constraining $\gamma_{1}=0.75$, which is the value that we obtain when we estimate this coefficient over the 1980-2006 period for our sample of countries, using a robust application (see Desbordes and Verardi (2011)) of the Anderson and Hsiao (1981) dynamic panel data estimator. ${ }^{4}$

\section{Empirical results}

\subsection{Baseline results}

Our initial empirical results are presented in Table 7. For each measure of democracy, we provide the classical FE estimates, the robust dummy (R-FE) estimates, and, for comparison, Maronna and Yohai (2000) M-S estimates.

Supporters of democracy would find the FE estimates extremely disappointing as no democratic attribute appears to exert a substantial and statistically significant effect on FDI. Furthermore, it is disconcerting to find that GDP, the most robust FDI determinant in the literature, is not statistically significant. On the other hand, the R-FE estimates paint a much different and nuanced picture. For most proxies, democracy appears to have a positive and statistically significant impact on FDI. A one standard deviation increase in democracy would increase FDI by about 3-10\% in the short run. These effects are not negligible since they are equivalent to a 20-40\% rise in GDP (holding population constant), which is now also a statistically significant determinant of FDI, along with population. Foreign investors seem to be particularly attracted by countries in which political decisions become more constrained by institutional checks and balances and greater media freedom. Column (8') of Table 7 shows that a free press trumps other democratic attributes defining a 'liberal democracy', including checks and balances.

Media freedom does not necessarily coincide with free and fair elections $(r \approx 0.82)$ or the level of

\footnotetext{
${ }^{4}$ Due to data availability, the estimated empirical model did not include the World Bank governance measure of regulatory quality. Results are similar when we use different values within the $95 \%$ confidence interval $[0.77,0.84]$ of the coefficient.
} 


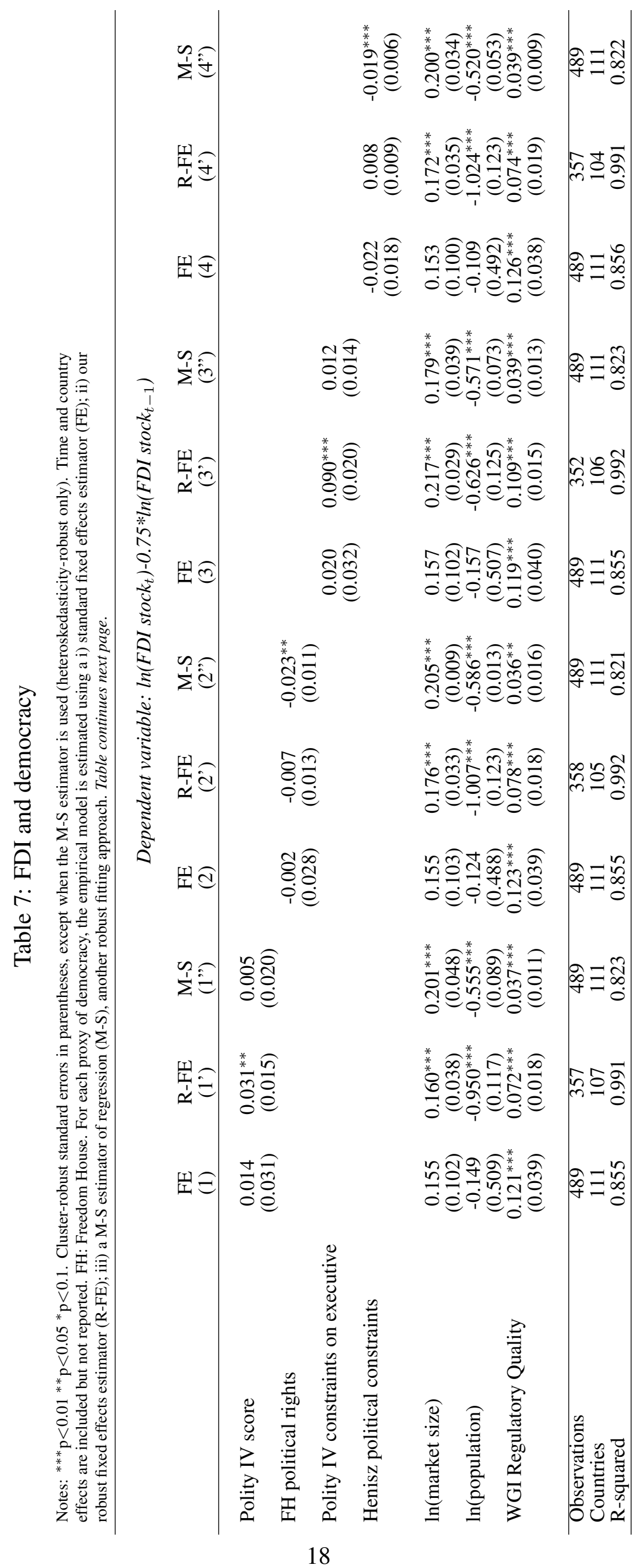




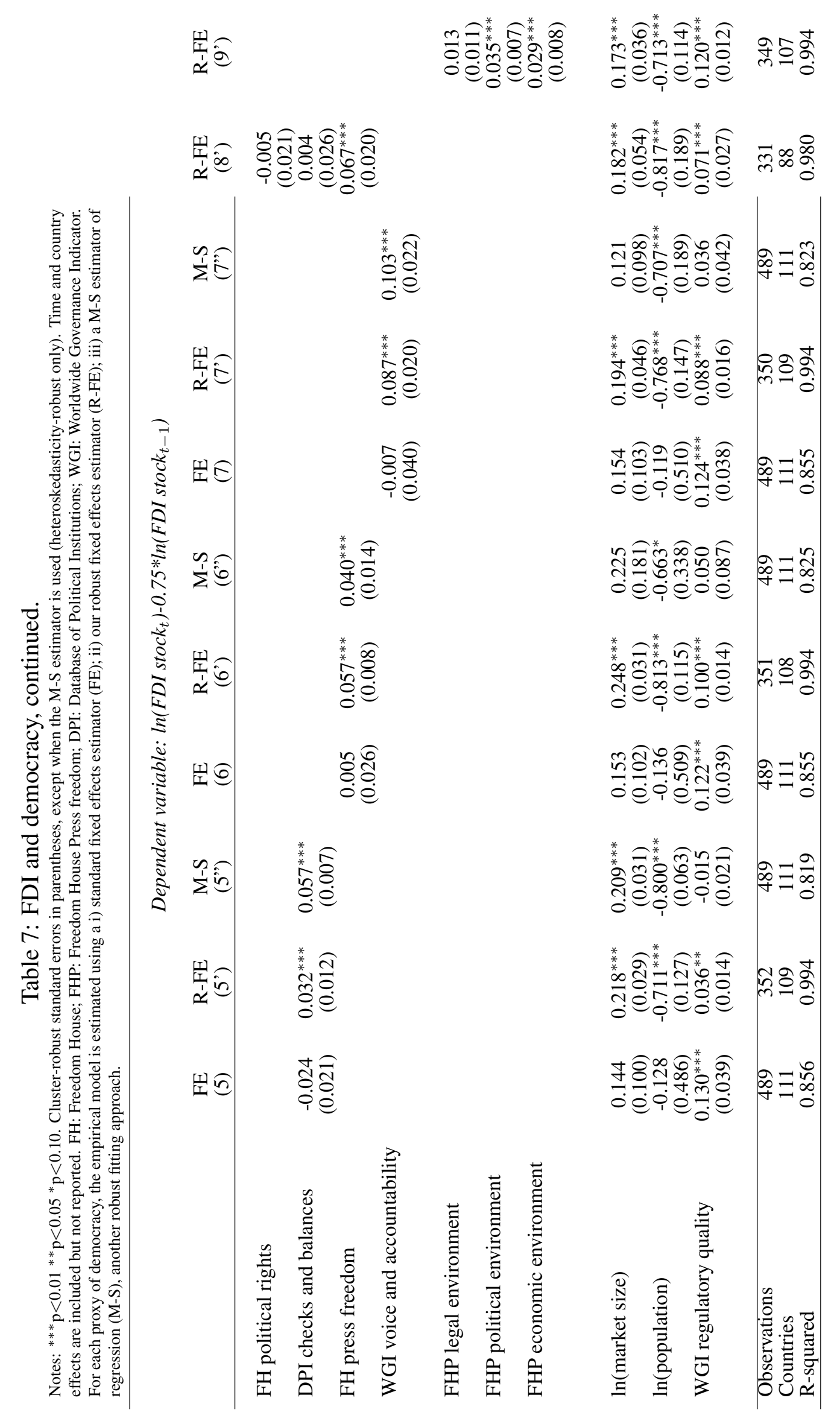


political constraints faced by policymakers $(r \approx 0.49)$. In other words, autocracies and (partially) free media seem compatible. Egorov, Guriev and Sonin (2009) suggest that this co-existence results from the need for an autocrat to obtain some independent feedback on the performance of the bureaucracy. In column (9') of Table 7, the FH Press Freedom index is decomposed into its three subcategories: 1) Legal environment which assesses "both and examination of the laws and regulations that could influence media content as well as the government's inclination to use these laws and legal institutions in order to restrict the media's ability to operate"; 2) Political environment which measures "the degree of political control over the content of news media"; 3) Economic environment which is related to "the economic considerations that can influence the media's activities" (Freedom House (2010a), pp. 12-13). Only the last two dimensions appear to be significant FDI determinants. Freille, Haque and Kneller (2007) find a similar outcome when investigating the impact of media freedom on corruption. Overall, these results suggest that the key factor which explains why democracies attract more FDI than autocracies is their tendency to exhibit greater media freedom, which presumably restrains bureaucratic corruption and enhances policy transparency. From another perspective, an autocracy can be as successful as a democracy in terms of attracting FDI as long as these two outcomes are met; the success of Singapore immediately comes to mind.

The other dimension of public governance, regulatory quality, always exerts a positive and statistically significant impact on FDI, whatever the estimator used, although its influence appears to be smaller when outliers are controlled for. Based on column (6'), a one standard deviation improvement in the quality of regulations would have about twice the short-run positive impact as a one standard deviation move towards more media freedom (10\%). Amin and Djankov (2009) show that democratic regimes tend to favour pro-business microeconomic reforms. On this basis, it is likely that the direct impact of democracy on FDI that we have estimated represents a lower bound effect since it does not account for the positive impact of democracy via better regulatory quality.

For each regression, about $28 \%$ of the observations are flagged as outliers by the R-FE estimator. As can be seen at the bottom of Table 7, many countries are occasionally outliers during the period 1996-2006. Predominant sources of R-FE and M-S outliers for regressions (7') and (7') can be observed in Figure 6.1. This Figure indicates the countries for which the average standardised residual is outside the non-outlying range delimited by the two horizontal lines. When [only] the median standardised residual is also outside this range, a square [triangle] is used instead of a circle. The two estimators tend to identify the same countries as sources of large outliers although divergences 
occur. For example, the R-FE estimator considers that some observations related to Haiti are large outliers, whereas this is not the case for the MS estimator. The choice between these two estimators can be based on the R-squared values, reported at the bottom of Table 7. It can be seen that the R-FE estimator increases drastically the fit of the empirical model whereas this is not true for the MS-estimator. Hence, the former estimator seems more suitable to explain the typical response of FDI to democratic changes. ${ }^{5}$

The presence of few squares and triangles in the left and right panels of Figure 6 shows that very few countries are block concentrated outliers (Bramati and Croux, 2007), i.e. for most countries, the volume of FDI that they received was, most of the time, well predicted by the empirical model estimated. For regression (7), the block outliers are Djibouti and Lybia. Interestingly, the FDI performance of the so-called BRICS countries, ${ }^{6}$ which accounted for $48 \%$ of the change in total FDI liabilities during the sample period, does not appear to have been atypical, despite the fact that some studies have frequently suggested that they are outliers (Choi, 2009). Hence, contrary to some of the worries raised in the political science literature $(\mathrm{Li}, 2009)$, the use of robust regression methods does not necessarily imply a drastic loss of coverage of the activities of foreign investors. Large FDI recipients are not necessary outliers, as long as the empirical model is reasonably well specified.

The use of summary statistics in Figure 6.1 is not informative about the FDI trajectory of 'atypical' countries and obscures the fact that not all observations related to these countries are outliers. Figure 7 illustrates these two issues by plotting the yearly standardised residuals for four countries previously flagged as source of outliers. It shows that the empirical model was unable to explain the large fluctuations in FDI received by countries like Botswana (BWA) or Zambia (ZMB) over the period 1998-2006 or the greater attractiveness of Zambia (ZMB) or Tajikistan (TJK) after the year 2002. Figure 7 reflects the difficulty for the researcher to model the economic developments of heterogenous countries with a parsimonious set of control variables; the empirical model may explain well the average response but necessarily struggle to account for country-specific idiosyncracies.

\subsection{Democracy and natural resources}

In a recent paper, Asiedu and Lien (2011) argue that democracy promotes FDI only in non-resource exporting countries. Their rationale, supported by their empirical analysis is that, in resource-exporting

\footnotetext{
${ }^{5}$ An additional advantage of our estimator is that it allows easy correction of the standard errors for clustering.

${ }^{6}$ BRICS countries are Brazil, Russia), India, China, and South Africa).
} 

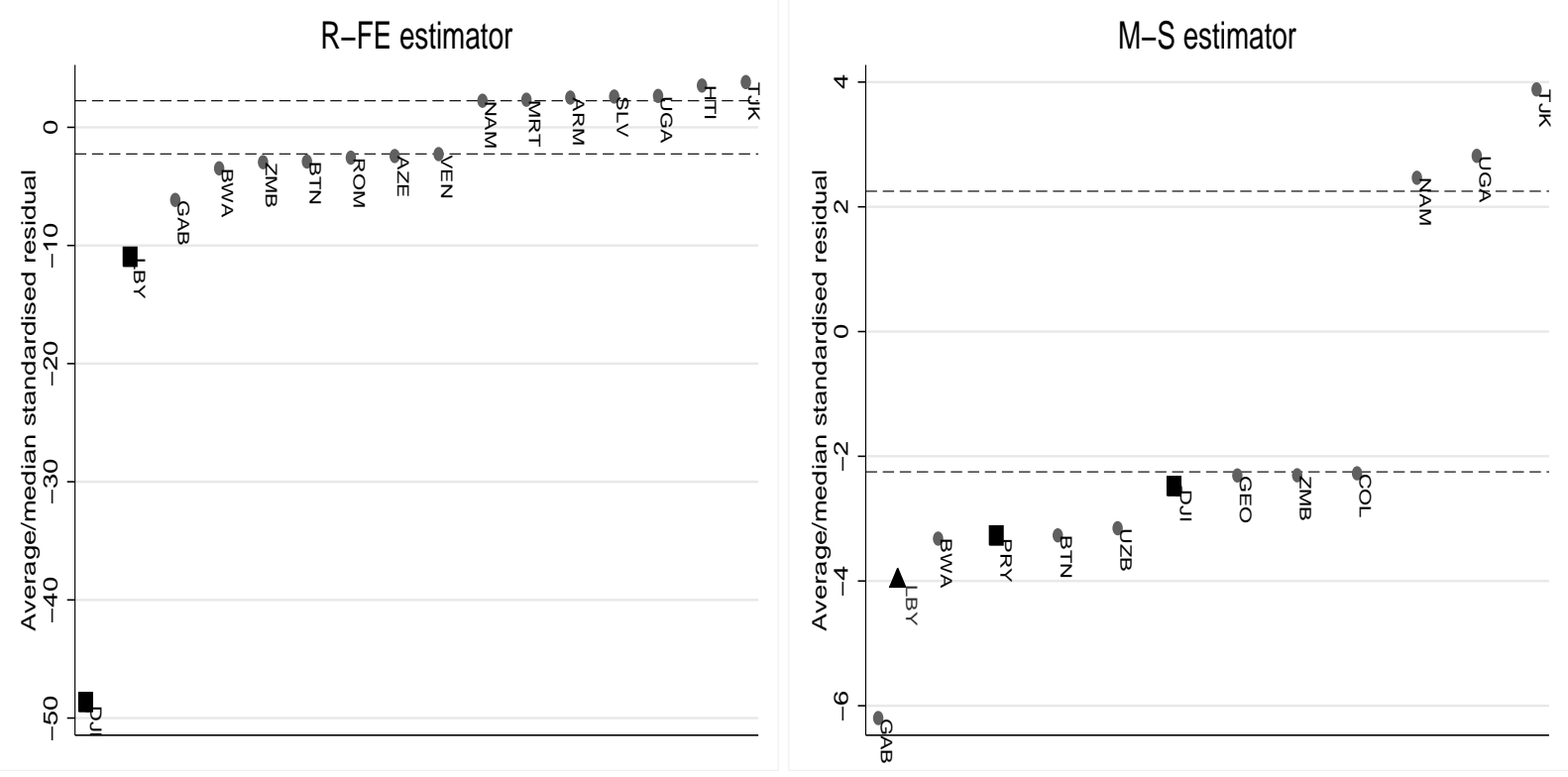

Notes: Circle: value of the average standardised residual smaller than -2.25 or greater than 2.25 . Triangle: value of the median standardised residual smaller than -2.25 or greater than 2.25. Square: values of both the average and median standardised residuals smaller than -2.25 or greater than 2.25 .

Figure 6: Identification of outliers

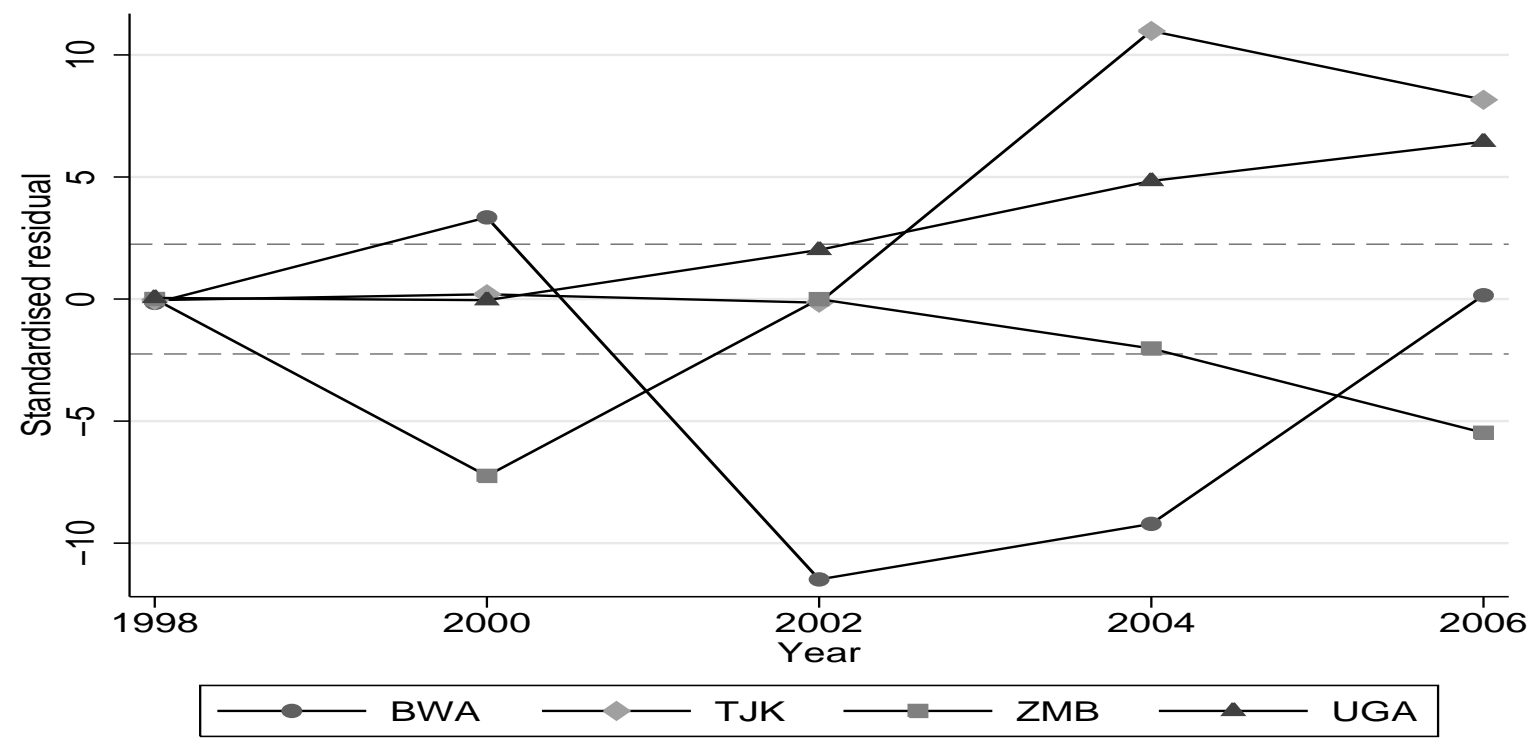

Figure 7: FDI attractiveness of four atypical countries 
countries, which tend to attract FDI mainly concentrated in extractive industries, foreign investors prefer the stability and easy access to natural resources that an autocracy presumably offers. This is a remarkable finding as it goes against the alleged benefits of democracy outlined in the introduction and because Guriev, Kolotilin and Sonin (2011) and Jensen and Johnston (2011) have shown that autocracies are more likely to expropriate foreign investors, including in the petroleum, natural gas and mining sectors. Nevertheless, we re-estimate our econometric model, which now includes Asiedu and Lien (2011)'s proxy for natural resource rich countries, the share of fuel and minerals in total merchandise exports, and its interaction with our different measures of democracy. Data on exports come from UNCTAD. ${ }^{7}$

Table 8 shows that estimates based on the classical FE estimator would, to a certain extent, support Asiedu and Lien (2011)'s arguments. However, once again, the R-FE estimates tell a different story. In most regressions, the coefficient on the interaction term is positive, large, and statistically significant, indicating that the higher a country's natural resource export intensity, the more positive the effect of democracy on FDI. Figure 8 summarises the relationship between the effect of democracy on FDI and natural resources abundance; the impact of democracy is presented at different deciles of the share of fuel and minerals in total merchandise exports. For high levels of natural resources, whichever the measure of democracy employed, the impact of greater democracy is positive, statistically significant, and substantially much larger than in resource-poor countries.

The negative association between violent conflicts and democracy may explain why the latter matters particularly for FDI in extractive industries. Given the high sunk costs that foreign firms in the mining and oil sectors incur, they are likely to be strongly deterred by violent sociopolitical instability and other forms of destructive conflicts, e.g. riots and guerilla warfare, which threaten their assets (Barham, Chavas and Coomes, 1998). Democracy may reduce social and political unrest, which may also be more likely in resource-exporting countries.

From an exogenous perspective, it can be expected that democracy provides to dissatisfied groups both the political opportunity to become actively involved into the decision-making progress and peaceful channels of expression to voice their grievances (Rummel, 1995; Ellingsen, 2000). Hence, stronger checks and balances, which may not only proxy for policy stability but also for the degree of political inclusiveness (Reynal-Querol, 2005), and media freedom, may guarantee that discontent is expressed in non-violent and destructive ways, e.g. protests (Przeworski et al., 2000; Pal, 2011). From

\footnotetext{
${ }^{7}$ http: //unctadstat.unctad.org/
} 


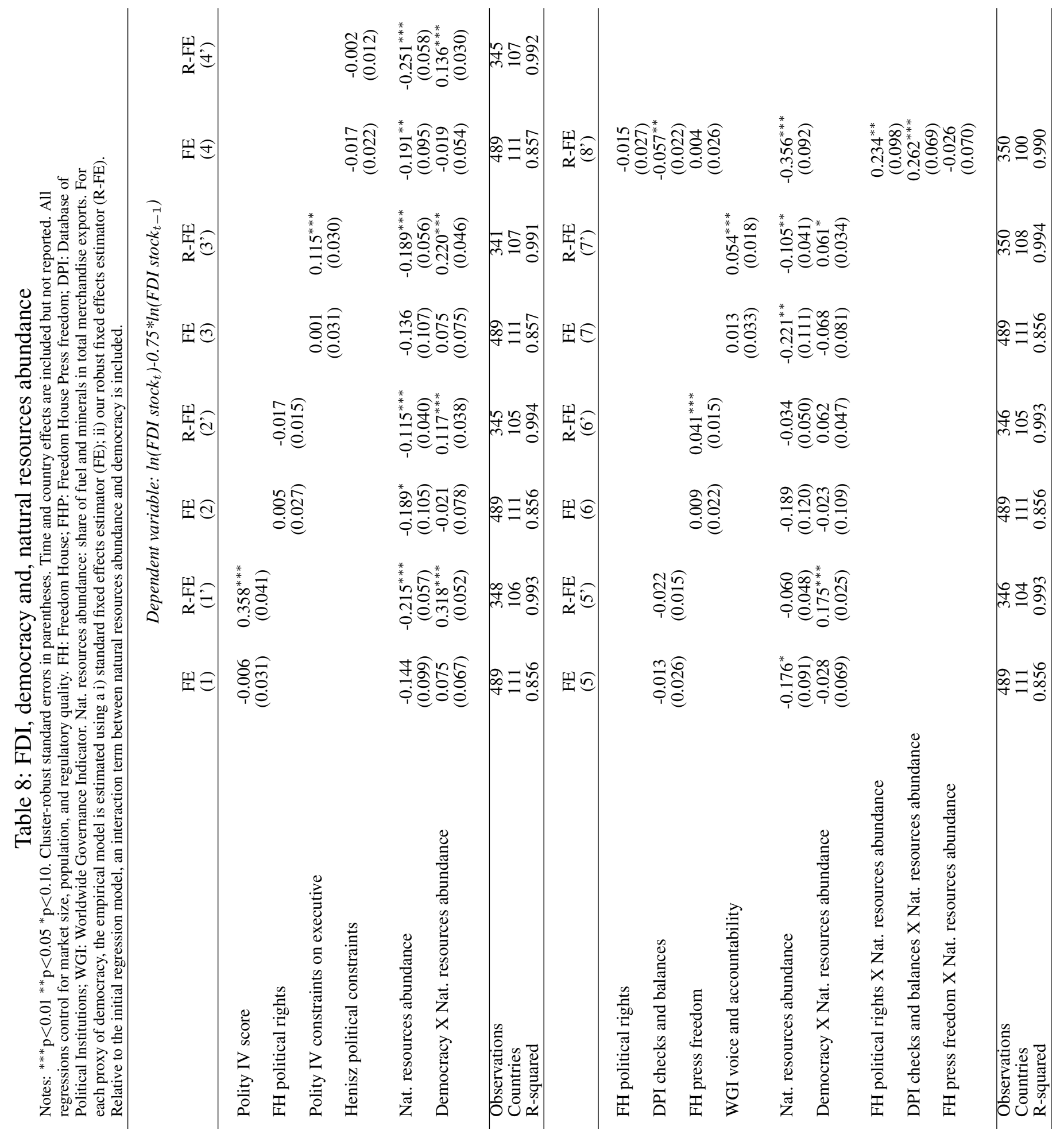


Figure 8: FDI in resource exporting countries and democracy
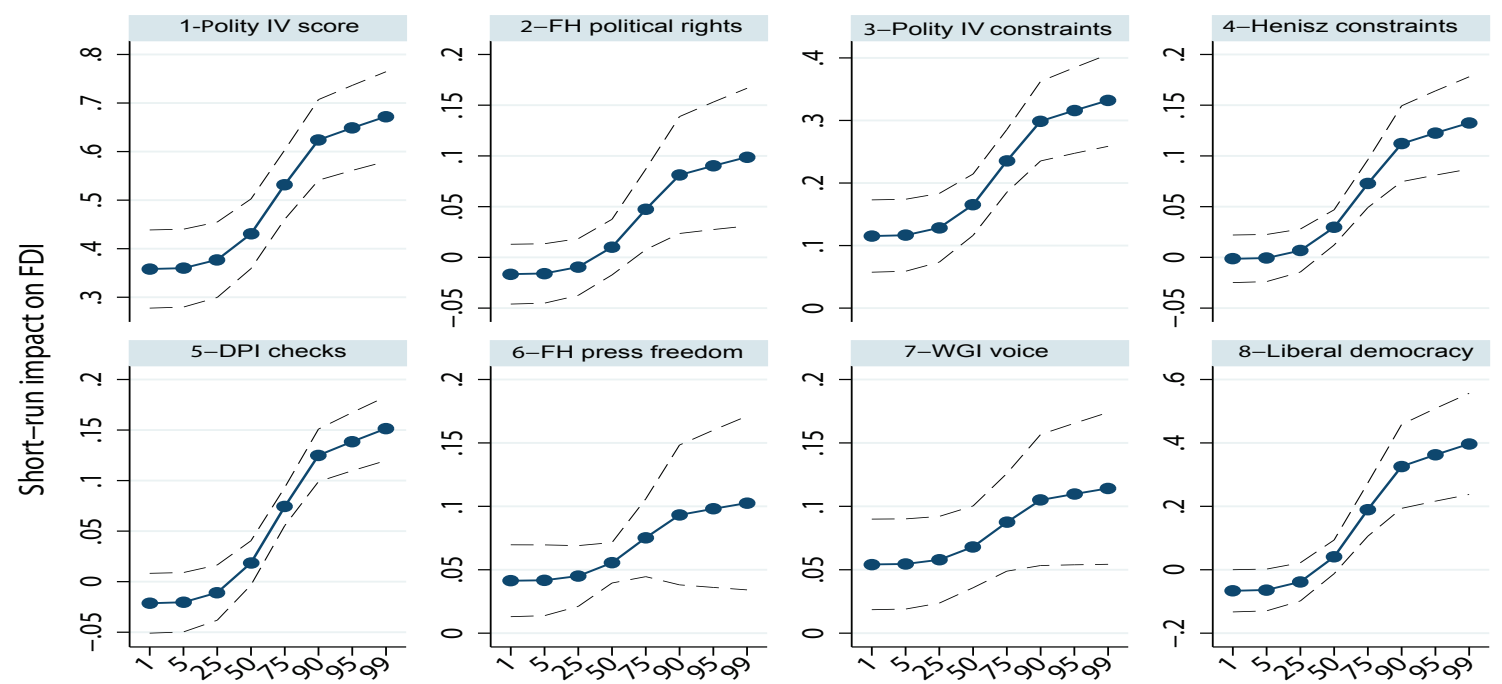

Percentile natural resources (Energy and mineral exports/Total exports)

Note: Dashed lines delimit the $95 \%$ confidence interval.

an endogenous perspective, democratisation may have been the rational choice of the elites that do not wish to be expropriated when faced with the likelihood of a revolution too costly to repress or to avoid via redistributive policies (Acemoglu and Robinson, 2006). Even though democracy and violence are again negatively correlated, it is the threat of the later which has triggered the emergence of the latter. Whichever the causality sense, the premium that FDI in extractive industries put on non-violence can explain their attractiveness for democracy.

\subsection{The mediating role of inequality}

It is possible that the link between FDI, democracy and natural resources depends on an additional factor. A prominent candidate from the growth literature is income inequality. In a textbook median voter model, greater income inequality leads to more demands for redistribution, resulting in more taxation (Alesina and Perotti, 1994). A government wishing to maximise its chances to be reelected would tend to avoid taxing domestic producers and therefore prefer to redistribute income via an increase in the tax burden of foreign investors, or other means of (creeping) expropriation (Caves, 1996; Desbordes and Vauday, 2007). In periods of high commodity prices, such as the 1998-2006 period, foreign firms in extractive industries are ideal targets as governments can easily argue that the visible windfall profits of those firms, unrelated to the intrinsic merit of their operative capabilities and generated by the exploitation of territorial resources, ought to be shared in a more balanced 
way. Furthermore, given the relatively scarcity of natural resources and the extremely high level of sunk costs required to extract, process and distribute them, capital mobility in these industries is low. Foreign firms cannot credibly threaten to move their operations abroad in response to an increase in taxation or the formulation of adverse policies. Hence, while democracy may reduce the risk of conflict, it may also increase regulatory uncertainty. We investigate this possibility by including in our model the Gini index of net income inequality and its interactions with democracy, natural resource export intensity and both. Data on the Gini coefficient come from Solt (2009).

Table 9 and Figure 9 summarise our results. ${ }^{8}$ The number of outliers remains about the same as in previous regressions (about 30\%), despite our adoption of a more flexible specification. A comparison of the classical and robust FE estimates shows again that results tend to be very different once the influence of outliers is controlled for. Focusing on the R-FE estimates, the impact of democracy on FDI is now less clear-cut than before as it is the product of the proxy used, natural resource export intensity and income inequality. As hypothesised, when a country's natural resource export intensity is high, the positive impact of democracy is weaker when income inequality is high. Foreign investors in the oil or mining industries presumably discount the benefits of more democracy by the probability of being confronted, now or once the investment has been 'sunk', with higher taxation or more stringent regulations.

For some measures, when a country's natural resource export intensity is low, democracy exerts its strongest positive impact on FDI when income inequality is high. Assuming that FDI in extractive industries is relatively low, this effect can be interpreted as the belief that democratic progress, in addition to all the previously mentioned benefits, will favour socio-political stability, while high capital mobility ought to deter greater taxation of foreign firms.

Remarkably, in high resource exporting/income inequality countries, greater press freedom seems to deter FDI. That is possibly because more press freedom allows the emergence, persistence and dissemination of redistribution demands beyond the election date. In other words, it is possible that media freedom acts as a commitment device, guaranteeing that politicians hold their electoral promises (Besley, Burgess and Prat, 2002). Column (8') of Table 9 and Figure 9 (bottom right) show that this negative impact of greater media freedom outweighs the positive impact of other democratic attributes when both natural resources and income inequality are high. The recent expropriations, nationalisations, forced renegotiations of contracts and higher taxes and royalties that foreign firms operating in

\footnotetext{
${ }^{8}$ For clarity's sake, confidence intervals are not reported in Figure 9.
} 


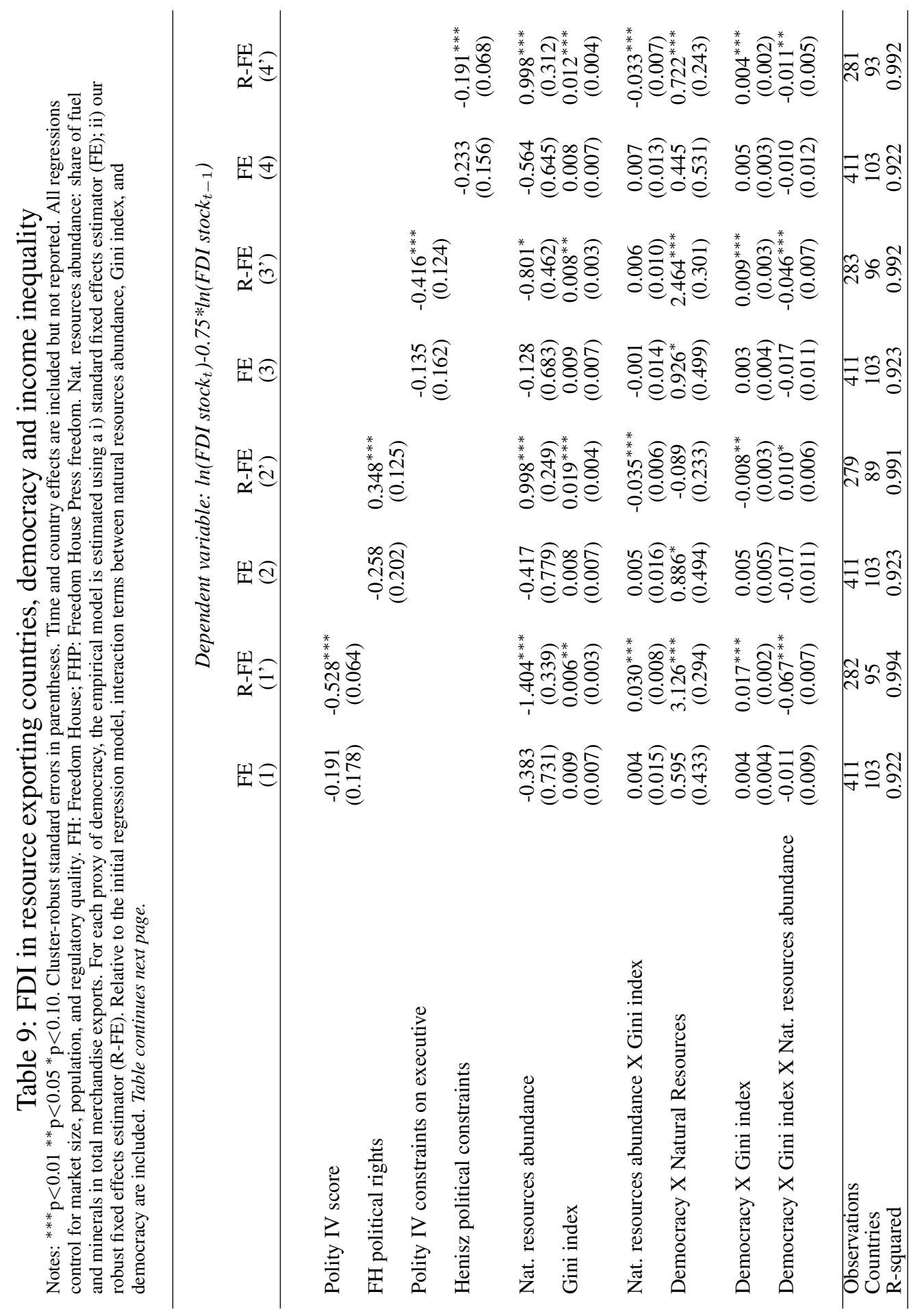




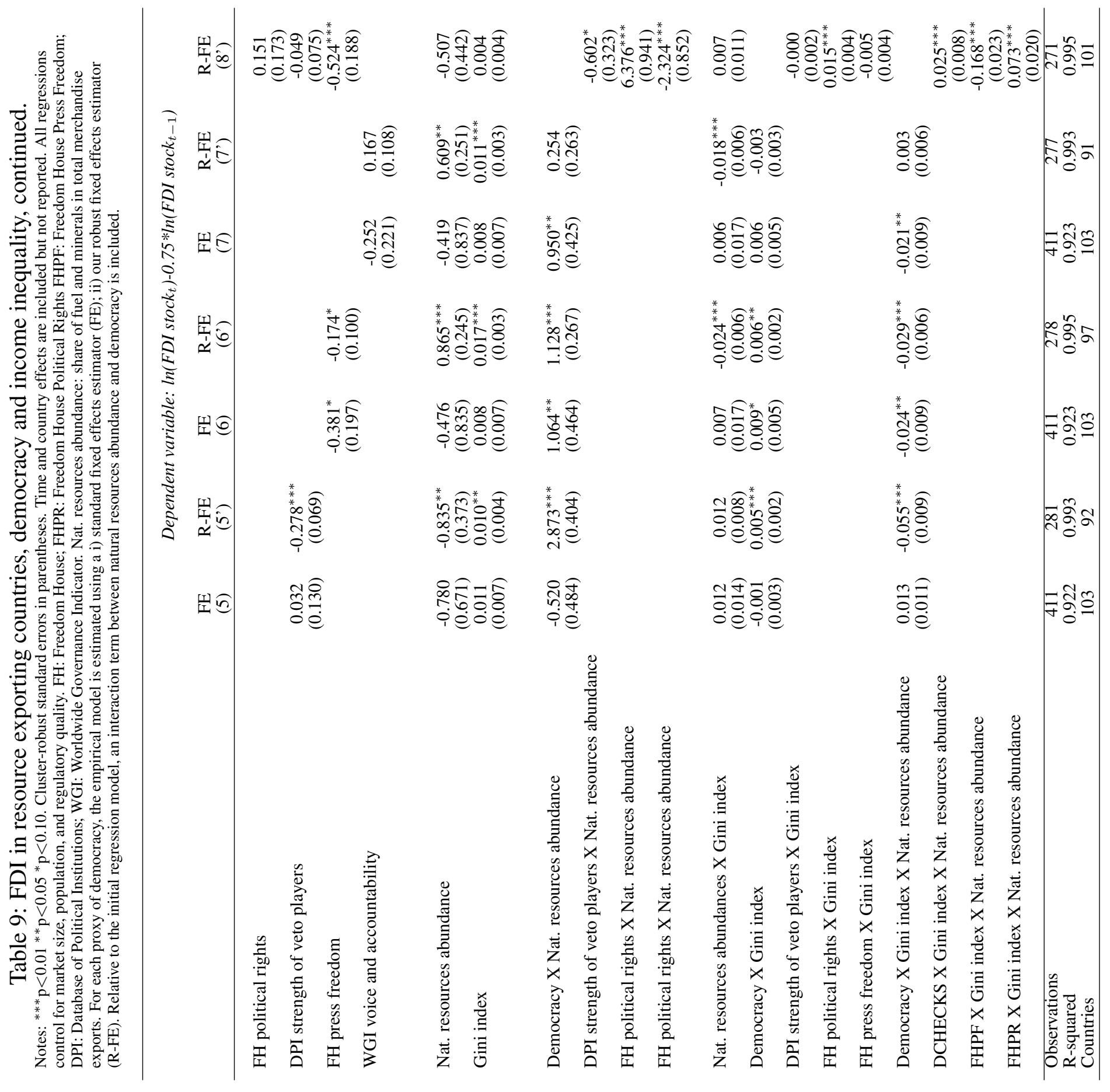


Figure 9: FDI in resource exporting countries, democracy and income inequality

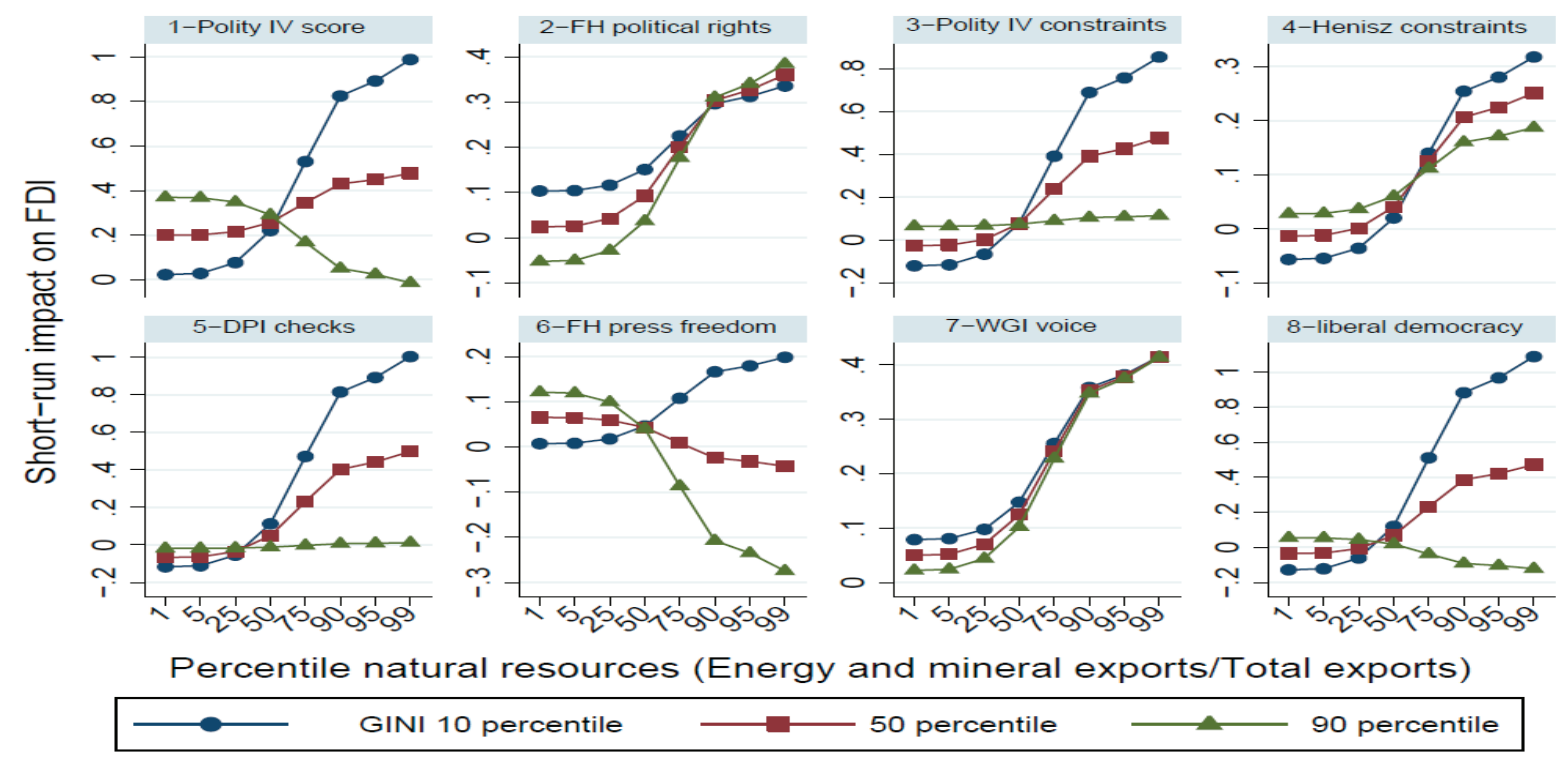

extractive industries have endured in relatively democratic countries meeting these two criteria, e.g. Bolivia, Ecuador or Zambia, provide additional factual support to our hypothesis.

The coefficients on the proxies of democracies, in Tables 8 and 9, correspond to the impact of democratic changes when a country is characterised by an absence of natural resources and perfectly equal distribution of income. In this hypothetical case, stronger democracy often appears to deter FDI, e.g column (1') in Table 9. As shown in Figure 9, for low values of natural resource abundance, this is especially the case when the proxy for democracy corresponds to the degree of political constraints on policy change. This result shows again that the impact of a given democratic attribute on FDI is context-specific. When the threat of socio-political instability is low and foreign firms do not make high sunk costs to extract natural resources, multinational enterprises may be reluctant to invest in countries where the likelihood of reforms becomes smaller due to a rise in veto players.

Before concluding, it is worth investigating whether our results would have been different if we had estimated our models with an M-S estimator. In the Appendix, Tables 10 and 11 report the M-S estimates and Figures 10 and 11 summarise the results. In Figure 10, it can be seen that we often fail to find that the effect of democracy on FDI is a function of natural resources abundance. In Figure 11, democracy tends to exert its highest impact in countries characterised by high income inequality and high natural resources abundance. These findings are different from those obtained using a RFE estimator. We can use the R-squared of the R-FE and M-S regression models to make a choice between the two sets of 'robust' results. The empirical models estimated by R-FE fit much better the 
data than those estimated by the M-S estimator; the average R-squared is 0.99 with the former and $0.82(0.87)$ for Figure 10) with the latter, worse than the R-squared obtained with the standard fixed effects estimator. On that basis, the results obtained using a R-FE estimators ought to be preferred.

\section{Conclusion}

The contributions of this paper have been two-fold. First, we developed a new robust-to-outliers dummy estimator, which ought to be extremely useful to applied economists, given the increasing preference for panel data fixed effects models in Economics. Second, we used this estimator to investigate the recent impact of democracy on foreign direct investment (FDI). We show that once outliers are controlled for, democratic attributes tend to attract FDI, especially when they are associated with stronger checks and balances, greater inclusiveness, or media freedom. Furthermore, we find that the positive effects of democracy are even larger when FDI is concentrated in natural resources. A plausible explanation is that democracy reduces the occurrence of violent conflicts, which are a major deterrent for FDI in extractive industries characterised by large sunk costs. Finally we put forward the case that other factors, such as income inequality, also play a mediating role in the relationship between FDI and democracy. Even though democracy may reduce social and political unrest in highly unequal societies, it may also trigger damaging redistributive policies for FDI in resource-abundant countries. Overall, this paper demonstrates that the impact of democracy on FDI is extremely complex an difficult to measure as it depends on the democratic attribute considered, the host country's characteristics, and the estimator used.

\section{References}

Acemoglu, Daron and James A. Robinson. 2006. Economic Origins of Dictatorships and Democracy. New York: Cambridge University Press.

Alesina, Alberto and Roberto Perotti. 1994. "The Political Economy of Growth: A Critical Survey of the Recent Literature.” World Bank Economic Review 8(3):351-71.

Amin, Mohammad and Simeon Djankov. 2009. "Democracy and Reforms." World Bank Policy Research Working Paper n $\hat{A}^{\circ} 4835$.

Anderson, T. W. and Cheng Hsiao. 1981. "Estimation of Dynamic Models with Error Component." Journal of the American Statistical Association 76(375):598-606. 
Aquaro, Michele and Cizek Pavel. 2010. "One-Step Robust Estimation of Fixed-Effects Panel Data Models." Tilburg University, Center for Economic Research Discussion Paper, nÂำ 2010-110.

Asiedu, Elizabeth and Donald Lien. 2011. "Democracy, foreign direct investment and natural resources." Journal of International Economics 84(1):99-111.

Azémar, Céline and Rodolphe Desbordes. 2009. "Public Governance, Health and Foreign Direct Investment in Sub-Saharan Africa." Journal of African Economies 18(4):667-709.

Barham, Bradford L., Jean-Paul Chavas and Oliver T. Coomes. 1998. "Sunk Costs and the Natural Resource Extraction Sector: Analytical Models and Historical Examples of Hysteresis and Strategic Behavior in the Americas." Land Economics 74(4):429-448.

Beck, Thorsten, George Clarke, Alberto Groff, Philip Keefer and Patrick Walsh. 2001. "New Tools in Comparative Political Economy: The Database of Political Institutions." World Bank Economic Review 15(1):165-176.

Benassy-Quere, Agnes, Maylis Coupet and Thierry Mayer. 2007. "Institutional Determinants of Foreign Direct Investment.” The World Economy 30(5):764-782.

Besley, Timothy, Robin Burgess and Andrea Prat. 2002. Mass Media and Political Accountability. In The Right to Tell: The Role of Mass Media in Economic Development, ed. Roumeen Islam, Simeon Djankov and Caralee McLeish. Washington D.C.: The World Bank.

Blanton, Shannon Lindsey and Robert G. Blanton. 2007. "What Attracts Foreign Investors? An Examination of Human Rights and Foreign Direct Investment." Journal of Politics 69(1):143-155.

Bramati, Maria C. and Christophe Croux. 2007. "Robust estimators for the fixed effects panel data model." The Econometrics Journal 10(3):521-540.

Busse, Mathias. 2004. "Transnational Corporations and Repression of Political Rights and Civil Liberties: An Empirical Analysis." Kyklos 57(1):45-65.

Busse, Matthias and Carsten Hefeker. 2007. "Political Risk, Institutions and Foreign Direct Investment.” European Journal of Political Economy 23(2):397-415.

Büthe, Tim and Helen V. Milner. 2008. "The Politics of Foreign Direct Investment into Developing Countries: Increasing FDI through International Trade Agreements?" American Journal of Political Science 52(4):741-762.

Caves, Richard E. 1996. Multinational Enterprises and Economic Analysis. Cambridge: Cambridge University Press.

Chakrabarti, Avik. 2001. "The Determinants of Foreign Direct Investments: Sensitivity Analyses of Cross-Country Regressions.” Kyklos 54(1):89-114.

Cheung, Yin-Wong and Xingwang Qian. 2009. "Empirics of China's Outward Direct Investment." Pacific Economic Review 14(3):312-341.

Choi, Seung-Whan. 2009. "The Effect of Outliers on Regression Analysis: Regime Type and Foreign Direct Investment." Quarterly Journal of Political Science 4(2):153-165. 
Choi, Seung-Whan and Yiagadeesen Samy. 2008. "Reexamining the Effect of Democratic Institutions on Inflows of Foreign Direct Investment in Developing Countries." Foreign Policy Analysis 4(1):83103.

Daude, Christian and Ernesto Stein. 2007. "The Quality of Institutions and Foreign Direct Investment." Economics and Politics 19(3):317-344.

Desbordes, Rodolphe and Julien Vauday. 2007. "The Political Influence of Foreign Firms in Developing Countries.” Economics \& Politics 19(3):421-451.

Desbordes, Rodolphe and Vincenzo Verardi. 2011. "The Positive Causal Impact of Foreign Direct Investment on Productivity: A Not So Typical Relationship.” Strathclyde Discussion Paper in Economics no. 11-06.

Egger, Peter and Valeria Merlo. 2007. "The Impact of Bilateral Investment Treaties on FDI Dynamics." The world economy 30(10):1536-1549.

Egorov, Georgy, Sergei Guriev and Konstantin Sonin. 2009. "Why Resource-poor Dictators Allow Freer Media: A Theory and Evidence from Panel Data." American Political Science Review 103(04):645-668.

Ellingsen, Tanja. 2000. “Colorful Community or Ethnic Witches' Brew?” Journal of Conflict Resolution 44(2):228-249.

Freedom House. 2010a. Freedom in the Press 2010: Broad Setback to Global Media Freedom. Available online at http://www. freedomhouse.org/uploads/pfs/371.pdf.

Freedom House. 2010b. Freedom in the World 2010: The Annual Survey of Political Rights and Civil Liberties. Lanham: Rowman \& Littlefield Publishers, Inc.

Freille, Sebastian, M. Emranul Haque and Richard Kneller. 2007. "A contribution to the Empirics of Press Freedom and Corruption.” European Journal of Political Economy 23(4):838-862.

Globerman, Steven and Daniel Shapiro. 2003. "Governance Infrastructure and U.S. Foreign Direct Investment.” Journal of International Business Studies 34(1):19-39.

Guriev, Sergei, Anton Kolotilin and Konstantin Sonin. 2011. "Determinants of Nationalization in the Oil Sector: A Theory and Evidence from Panel Data." Journal of Law, Economics, and Organization 27(2):301-323.

Harms, Philipp and Heinrich W. Ursprung. 2002. "Do Civil and Political Repression Really Boost Foreign Direct Investments?" Economic Inquiry 40(4):651-663.

Henisz, Witold J. 2000. “The Institutional Environment for Economic Growth.” Economics and Politics 12(1):1-31.

Hubert, Mia and Peter J. Rousseeuw. 1997. "Robust Regression With Both Continuous and Binary Regressors.” Journal of Statistical Planning and Inference 57(1):153-163.

Jakobsen, Jo and Indra De Soysa. 2006. "Do Foreign Investors Punish Democracy? Theory and Empirics, 1984ÂA-2001." Kyklos 53(3):383-410. 
Jensen, Nathan. 2008. "Political Risk, Democratic Institutions, and Foreign Direct Investment." Journal of Politics 70(4):1040-1052,.

Jensen, Nathan M. 2003. "Democratic Governance and Multinational Corporations: Political Regimes and Inflows of Foreign Direct Investment.” International Organization 57(3):587-616.

Jensen, Nathan M. and Noel P. Johnston. 2011. "Political Risk, Reputation, and the Resource Curse." Comparative Political Studies 44(6):662-688.

Kaufmann, Daniel, Aart Kraay and Massimo Mastruzzi. 2004. "Governance Matters III: Governance Indicators for 1996-2002.” World Bank Working Paper, nÂ 3106.

Kinoshita, Yuko and Ashoka Mody. 2001. "Private Information for Foreign Investment in Emerging Countries." The Canadian Journal of Economics 34(2):448-464.

Lane, Philip R. 2015. "International Financial Flows in Low-Income Countries." Pacific Economic Review 20(1):49-72.

Lane, Philip R. and Gian Maria Milesi-Ferretti. 2007. "The External Wealth of Nations Mark II: Revised and Extended Estimates of Foreign Assets and Liabilities, 1970-2004." Journal of International Economics 73(2):223-250.

Li, Quan. 2009. “Outlier, Measurement, and the Democracy-FDI Controversy.” Quarterly Journal of Political Science 4(2):167-181.

Li, Quan and Adam Resnick. 2003. "Reversal of Fortunes: Democratic Institutions and Foreign Direct Investment Inflows to Developing Countries.” International Organization 57(5):175-211.

Maronna, Ricardo A. and Victor J. Yohai. 2000. "Robust Regression with Both Continuous and Categorical Predictors.” Journal of Statistical Planning and Inference 89(1-2):197-214.

Marshall, Monty G., Ted R. Gurr and Keith Jaggers. 2010. Polity IV Project: Political Regime Characteristics and Transitions, 1800-2009, Dataset UsersÂ' Manual. Center for Systemic Peace.

Munck, Gerardo L. and Jay Verkuilen. 2002. "Conceptualizing and Measuring Democracy." Comparative Political Studies 35(1):5-34.

Nickell, Stephen J. 1981. "Biases in Dynamic Models with Fixed Effects.” Econometrica 49(6):141726.

Pal, Sudeshna. 2011. "Media Freedom and Socio-Political Instability.” Peace Economics, Peace Science and Public Policy 17(1):1-21.

Przeworski, Adam, Michael E. Alvarez, José A. Cheibub and Fernando Limongi. 2000. Democracy and Development. Political Institutions and Well-Being in the World, 1950-1990. New York: Cambridge University Press.

Reynal-Querol, Marta. 2005. "Does democracy preempt civil wars?" European Journal of Political Economy 21(2):445-465.

Rousseeuw, Peter J. and Joachim Wagner. 1994. "Robust Regression With a Distributed Intercept Using Least Median of Squares.” Computational Statistics \& Data Analysis 17(1):65-76. 
Rousseuw, Peter J. and Victor J. Yohai. 1984. Robust and Nonlinear Time Series Analysis, Lecture Notes in Statistics No. 26. In Investing in the United States, ed. W. Franke, W. Hardle and R. D. Martin.

Rummel, Rudolph J. 1995. "Democracy, Power, Genocide, and Mass Murder." Journal of Conflict Resolution 39(1):3-26.

Schumpeter, Joseph A. 1942. Capitalism, Socialism and Democracy. New York: Harper \& Brothers.

Solt, Frederick. 2009. “Standardizing the World Income Inequality Database." Social Science Quarterly 90(2):231-242.

Van Belle, Douglas A. 1997. "Press Freedom and the Semocratic Peace." Journal of Peace Research 34(4):405-414.

Verardi, Vincenzo and Christophe Croux. 2009. "Robust regression in Stata.” Stata Journal 9(3):439453. 


\section{Appendix: algorithm for the robust identification of outliers}

Intuitively, the LS estimator of $\theta$ is $\hat{\theta}_{L S}=(\underbrace{X^{-1}}_{\sum_{X X} X^{\prime} X} \underbrace{}_{\sum_{X y} X^{\prime} y}$, where $\sum_{X X}$ and $\sum_{X y}$ are respectively $n$ times the covariance of $X$ and $(X, y)$. If we replace $\sum_{X X}$ and $\sum_{X y}$ by some robust counterparts, this estimator will become resistant to outliers. Hence, we propose to use the Stahel-Donoho estimate (see (Maronna and Yohai, 2000)) to identify and remove multivariate outliers in the set $M=(y, X)=$ $\left(y, X_{1}, X_{2}\right)$ and obtain robust $\hat{\sum_{X X}}$ and $\hat{\sum_{X y}}$. Once we have preliminary estimates for parameters $\theta$ and residuals $r_{i}$, we can use an iterative algorithm to find a solution to (3).

Our algorithm is therefore:

1. Use a multivariate outlier detection tool (more precisely, as suggested by Maronna and Yohai (2000), the Stahel-Donoho estimate) to measure the "outlyingness" of each individual considering the data cloud $M=\left(y, X_{1}, X_{2}\right)$. This estimator is a multivariate outlier identification tool based on univariate projections. Outlyingness distances correspond to the largest distance of each point with respect to a center of the projected data cloud when considering all possible directions for the projections. The effect of dummies is partialled-out in each projection. This has the advantage of taking into account the effect of dummies, but without facing the issue of collinear subsamples. ${ }^{9}$ Since these distances are distributed for Gaussian data as $\sqrt{\chi_{p_{2}+1}^{2}}$ we can flag individuals as being outliers when their outlyingness distance is larger than a given quantile of $\sqrt{\chi_{p_{2}+1}^{2}}$ (generally the $95^{\text {th }}$ or $99^{\text {th }}$ percentile). ${ }^{10}$

2. Apply a weight zero to all the outliers, and use a standard LS estimator to fit the model robustly and to estimate "robust" residuals for all observations.

3. Use the robust residuals to start a standard iterative algorithm. Note that dummies are now treated like the other explanatory variables since no subsampling is needed anymore.

\section{MS estimates}

Tables 10 and 11 report the M-S estimates. Figures 10 and 11 summarise the results.

\footnotetext{
${ }^{9}$ See Maronna and Yohai (2000) for further details.

${ }^{10}$ Note that the degrees of freedom is $p_{2}+1$ and not $p+1$ because dummy variables will be partialled-out.
} 


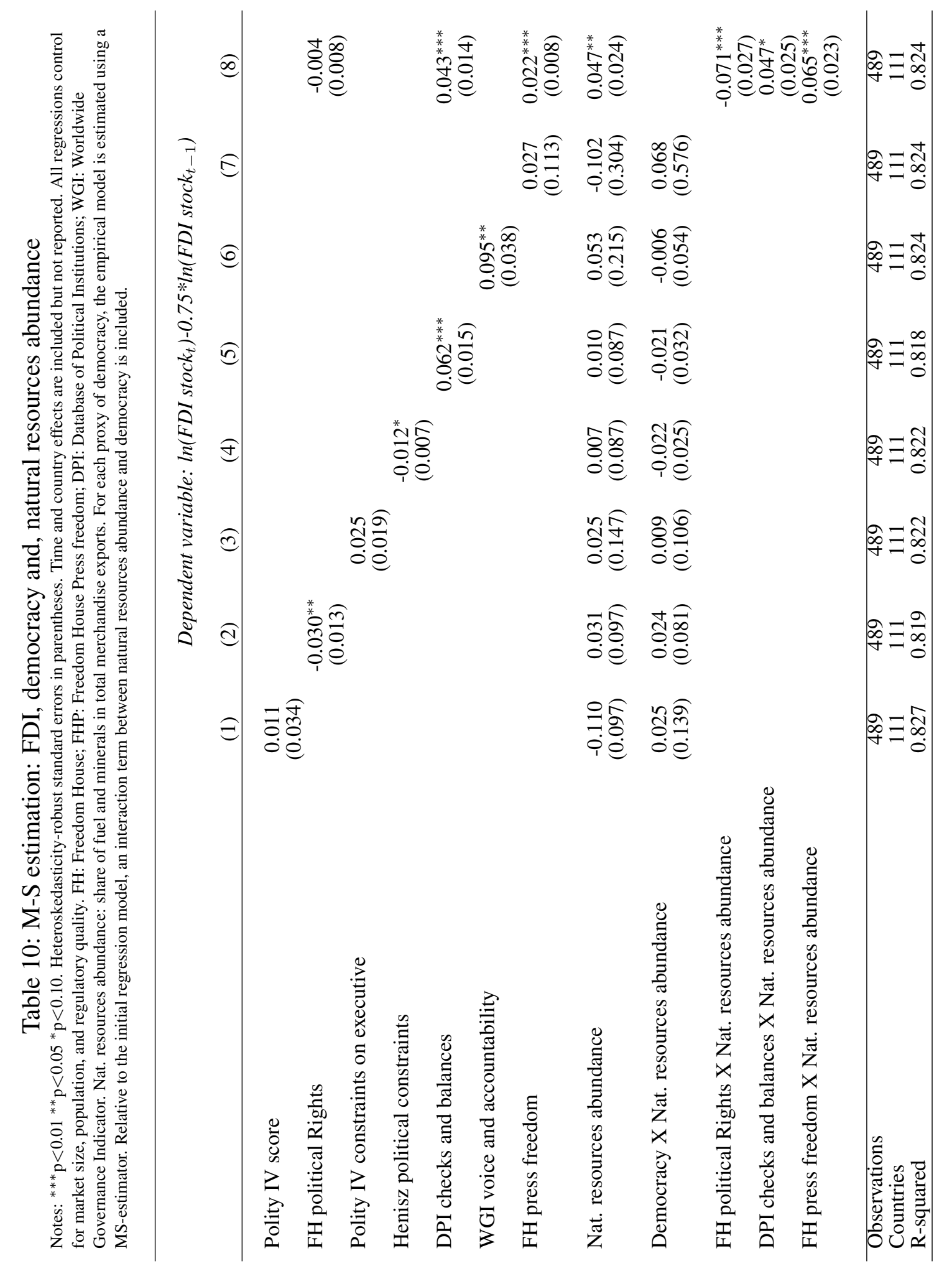




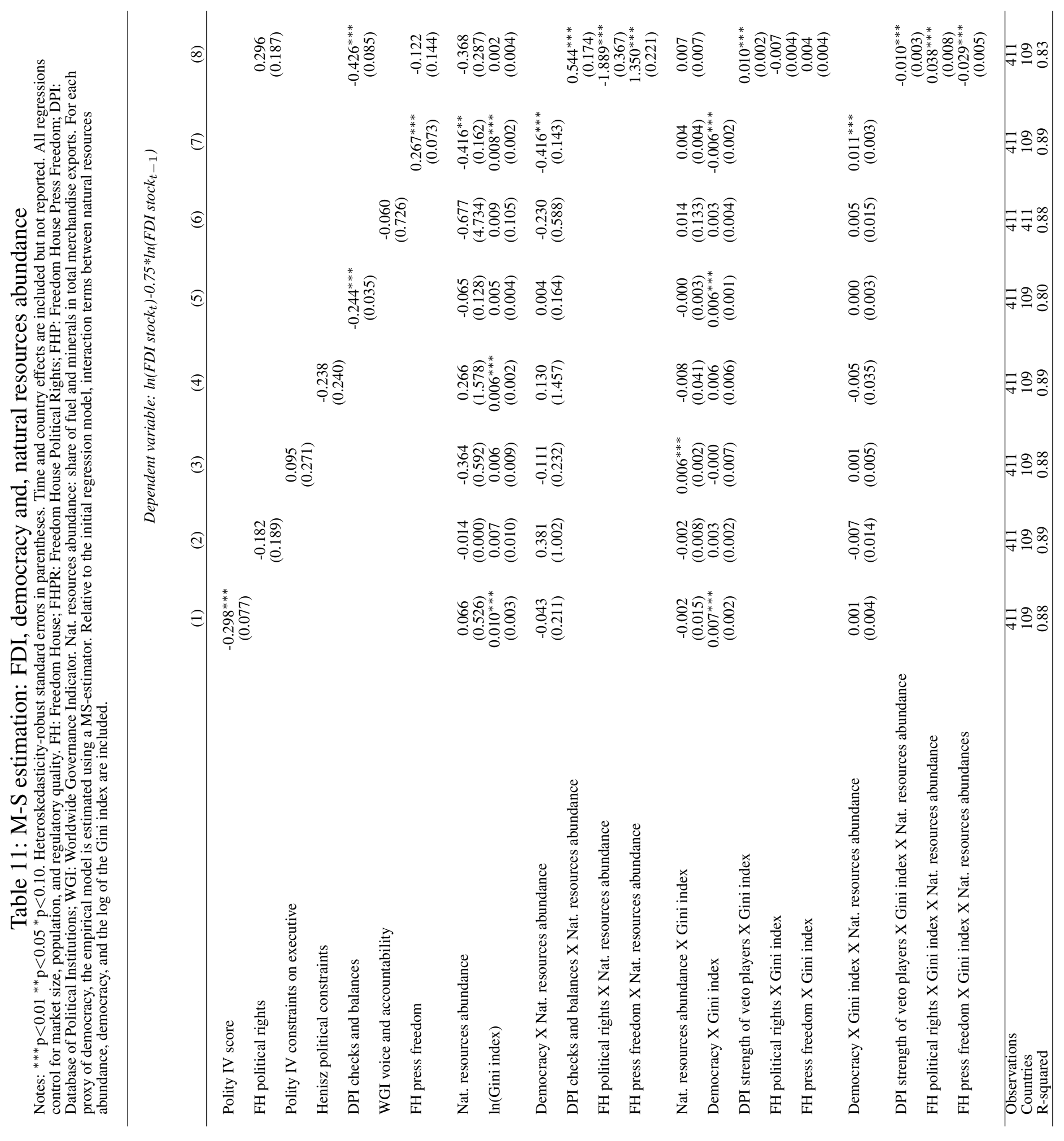


Figure 10: M-S estimation: FDI, democracy and natural resources

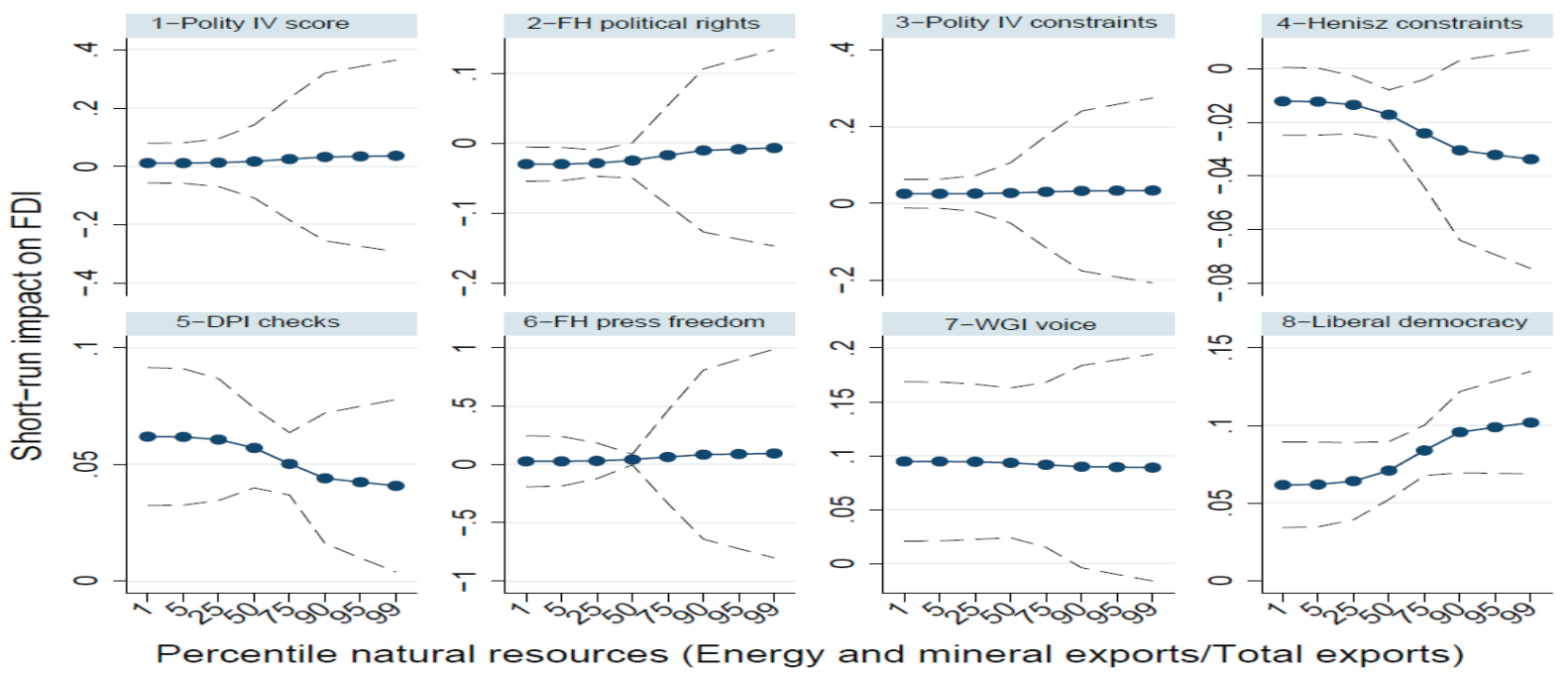

Note: Dashed lines delimit the 95\% confidence interval.

Figure 11: M-S estimation: the mediating role of inequality

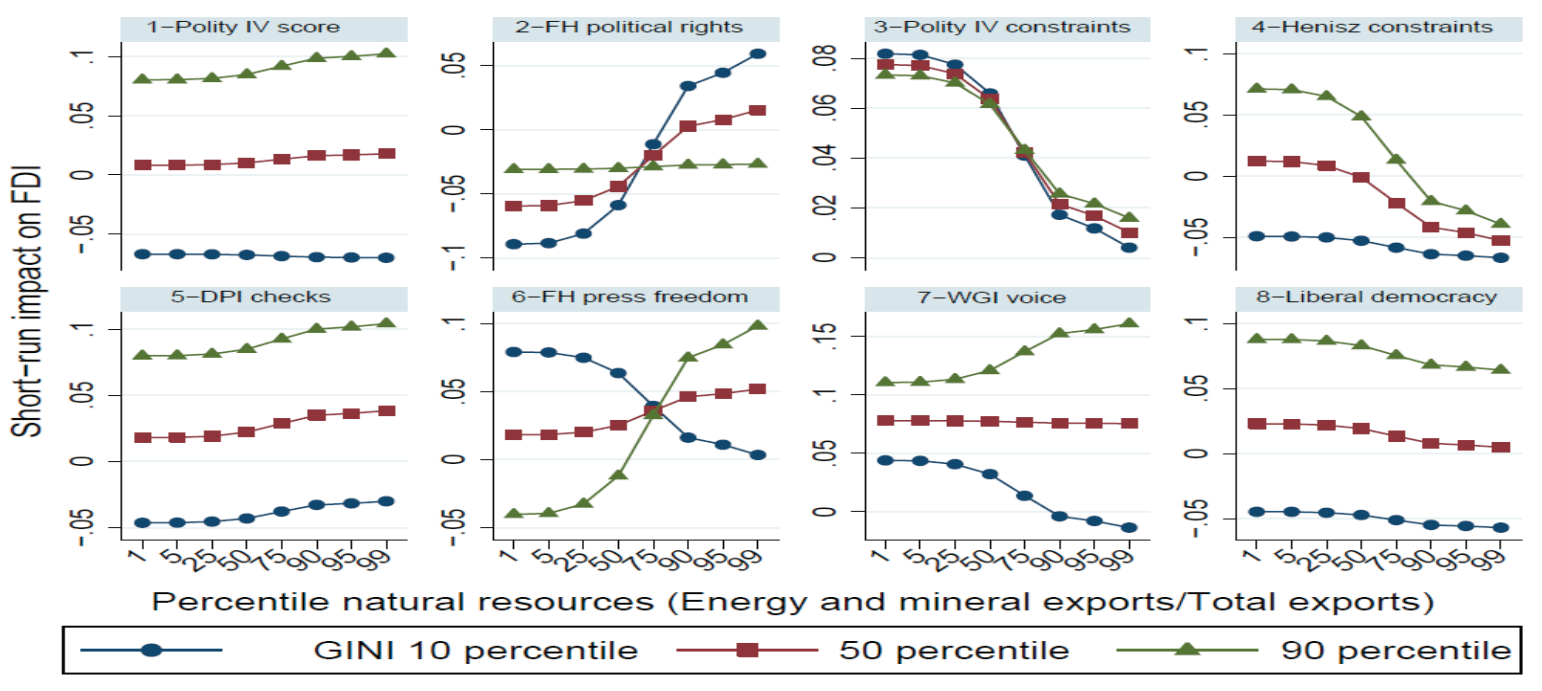

